Utah State University

DigitalCommons@USU

$5-2014$

\title{
Bay of Bengal: Coupling of Pre-Monsoon Tropical Cyclones With the Monsoon Onset in Myanmar
}

Boniface Opoku Fosu

Utah State University

Follow this and additional works at: https://digitalcommons.usu.edu/etd

Part of the Climate Commons

\section{Recommended Citation}

Fosu, Boniface Opoku, "Bay of Bengal: Coupling of Pre-Monsoon Tropical Cyclones With the Monsoon Onset in Myanmar" (2014). All Graduate Theses and Dissertations. 3864.

https://digitalcommons.usu.edu/etd/3864

This Thesis is brought to you for free and open access by the Graduate Studies at DigitalCommons@USU. It has been accepted for inclusion in All Graduate Theses and Dissertations by an authorized administrator of DigitalCommons@USU. For more information, please contact digitalcommons@usu.edu.

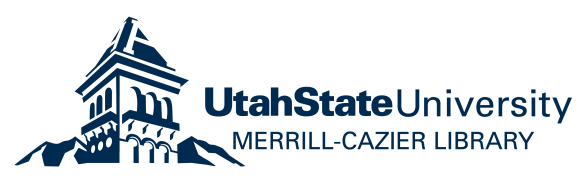




\section{BAY OF BENGAL: COUPLING OF PRE-MONSOON TROPICAL CYCLONES WITH THE MONSOON ONSET IN MYANMAR}

by

Boniface O. Fosu

A thesis submitted in partial fulfillment

of the requirements for the degree

of

MASTER OF SCIENCE

in

Climate Science

Approved:

Shih-Yu Wang

Robert Gillies

Major Professor

Committee member

Brendan M. Buckley

Vice President for Research and

Committee Member

Dean of the School of Graduate Studies

\section{UTAH STATE UNIVERSITY}

Logan, Utah 
Copyright (C) Boniface O. Fosu

All Rights Reserved 


\author{
ABSTRACT \\ Monsoon Onset in Myanmar \\ by \\ Boniface O. Fosu, Master of Science \\ Utah State University, 2014
}

Bay of Bengal: Coupling of Pre-Monsoon Tropical Cyclones with the

Major Professor: Dr. Simon S. -Y. Wang

Department: Plants, Soils, and Climate

The pre-monsoon tropical cyclone (TC) activity and the monsoon evolution in the Bay of Bengal (BoB) are both influenced by the Madden Julian Oscillation (MJO), but the two do not always occur in unison. This study examines the conditions that allow the MJO to modulate the monsoon onset in Myanmar and TC activity concurrently. By using the APHRODITE gridded precipitation and the ERA-Interim reanalysis datasets, composite evolutions of monsoon rainfall and TC genesis are constructed for the period of 1979-2010. It is found that the MJO exhibits a strong interannual variability in terms of phase and intensity, which in some years modulate the conditions for BoB TCs to shortly precede or form concurrently with the monsoon onset in Myanmar. Such a modulation is absent in years of weaker MJO events. Further understanding of the interannual variability of MJO activity could facilitate the prediction of the monsoon onset and $\mathrm{TC}$ formation in the BoB. 


\section{PUBLIC ABSTRACT}

Bay Of Bengal: Coupling of Pre-Monsoon Tropical Cyclones with the

\section{Monsoon Onset in Myanmar}

Myanmar remained largely closed to the world through political instability for several years, when it continued to suffer terribly at the hands of nature that remained largely unknown. Of note is the period between 2008 and 2013, during which the country suffered at least eight major natural calamities that killed more than 141,000 people and affected 3.2 million. The worst of these was Cyclone Nargis in May 2008 that killed more than 130,000 . With an estimated $\$ 4$ billion in damages, Nargis remains the deadliest and most destructive named cyclone ever to have occurred in the North Indian

Ocean. Recent studies have shown that, due to increased greenhouse gases and aerosol loading in the atmosphere, more and stronger tropical cyclones (TCs) in the last three decades are tracking eastwards toward the Indochina peninsula. Unfortunately, the Burmese lack the capacity to deal with the impacts of such storms.

Myanmar was left behind as the world made significant technological and industrial advancement; but agriculture, which employs at least $65 \%$ of the active labor force, has remained the backbone of the Myanmar economy - an industry that is heavily reliant on monsoon rainfall. The pre-monsoon $\mathrm{TC}$ season in the Bay of Bengal $(\mathrm{BoB})$ precedes the onset of the Myanmar monsoon but sometimes the two (i.e.TC formation and the monsoon onset) occur in unison. This work studied the mechanism by which the Madden Julian Oscillation (MJO) modulates the Myanmar monsoon onset and $\mathrm{TC}$ activity collectively (i.e. ISO-Onset-TC connection). Avoiding TC destruction at the 
beginning of the planting season is crucial, so is the monsoon onset date critical for planning. Additional understanding of the aforementioned ISO-Onset-TC connection could provide further insight into predicting the Myanmar monsoon onset and aid in disaster planning for TC impact.

This research is part of a two-year NASA funded project to study extreme climate and weather events.

Boniface O. Fosu 


\begin{abstract}
AKNOWLEDGMENTS
I cannot express with enough words how grateful I am to Dr. Simon S. -Y. Wang for taking me as his student, and giving me the opportunity to pursue research in climate diagnostics and dynamics. His mentoring and unconditional support have been an invaluable part of my success in graduate school. If there is one person who has single handedly made a difference in my education, from pre-school to date, it is my advisor Simon.

I am very grateful to Dr. Robert Gillies and Dr. Brendan Buckley for taking time off their busy schedules to serve on my committee, and for all the assistance they provided at all levels of this project. I would also like to extend my sincere gratitude to Dr. Larry Hipps for playing an extremely important role throughout my graduate studies - a brilliant and discerning teacher from whom I have learnt many scientific concepts and ideas.
\end{abstract}

Last, but not least, I would like to thank my family for their unconditional love and solace, in particular my parents. I would also like to express my heartfelt gratitude to Steve Wilkins and his family for their endless love and support. If it weren't for you, I would never have made it here in the first place. To my childhood, college, and graduate school friends, I say a very big thank you.

Boniface O. Fosu 


\section{CONTENTS}

Page

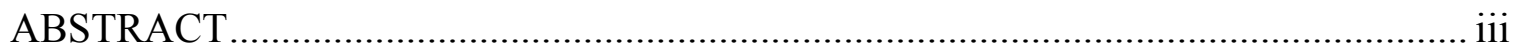

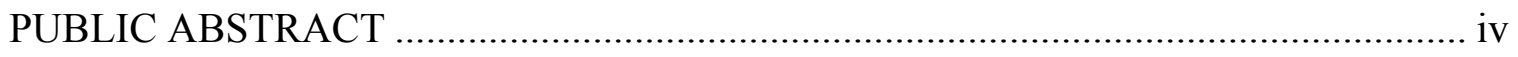

ACKNOWLEDGEMENTS ............................................................................. vi

LIST OF FIGURES ..................................................................................... viii

\section{CHAPTER}

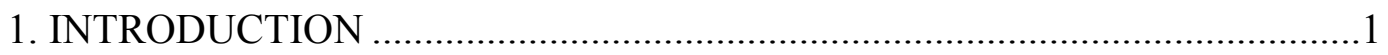

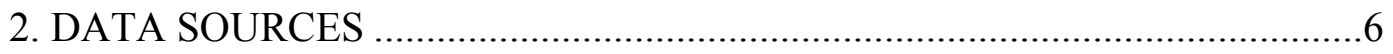

3. ANALYSIS PROCEDURES ....................................................................

3.1 Onset selection ............................................................................ 7

3.2 Velocity potential and streamfunction representation of the MJO ........8

3.3 Composite evolution of the monsoon, and TCs...............................12

3.4 EOF representation of the MJO ................................................... 17

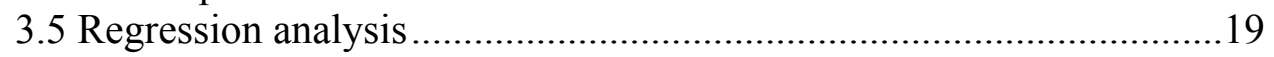

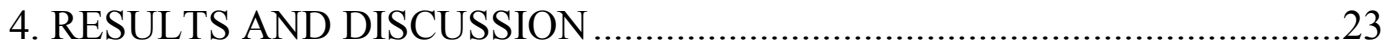

4.1 ISO - Onset connection ............................................................2 23

4.2 ISO - TC connection .................................................................22

4.3 ISO - Onset - TC connection .....................................................24

4.4 MJO phase, magnitude and amplitude ...........................................26

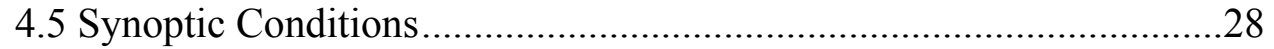

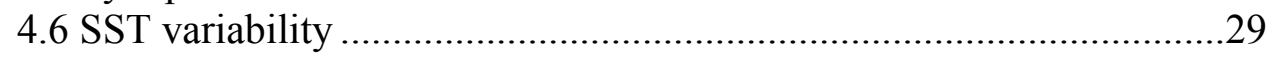

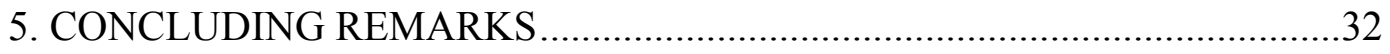

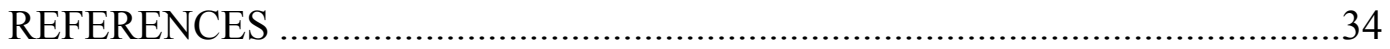




\section{LIST OF FIGURES}

Figure

Page

1 a Mean 850-mb streamfunction ( $\Psi$ ) (contour interval: $1.210^{6} \mathrm{~m}^{2} \mathrm{~s}^{-1}$ ) of May, overlaid with all post 1979 spring cyclogenesis locations (red typhoon symbols) in the BoB. b Tropical storm count in the BoB and rainfall distribution averaged from the orange box in a (western and central Myanmar). Hurricane force storms (red bars) are cyclones with winds speeds greater than $107 \mathrm{~km} / \mathrm{h}$.

2 850-hPa unfiltered $\Psi$ fields (shaded), superimposed with 30-60 days bandpassed $\Psi$ (contours, interval: $0.710^{6} \mathrm{~m}^{2} \mathrm{~s}^{-1}$ ) averaged over longitude 80 100 E. Histograms of daily precipitation from April through July over western and central Myanmar for each year is overlaid in blue. Red and green lines show onset and tropical cyclogenesis dates respectively.

3 Schematic showing the variables used in calculating velocity potential and streamfunction in the equations described in section 5.2. L is defined as the chord distance between the two points $(\lambda, \phi)$ and $\left(\lambda^{\prime}, \phi^{\prime}\right)$ .11

a Composite evolution of daily rainfall averaged over western and central Myanmar. The average date of monsoon onset it May 20 (day 0, black line). b Composite evolution of $850-\mathrm{hPa}$ unfiltered $\Psi$ fields (shaded), superimposed with 30-60 days bandpassed $\Psi$ (contours) (contour interval: $1.610^{6} \mathrm{~m}^{2} \mathrm{~s}^{-1}$ ), averaged over longitude 80-100 E with the locations of all pre-monsoon tropical cyclogenesis (red typhoon symbols) superimposed. Cyclogenesis days are plotted relative to the composite onset, at the same latitude they occurred. The black box indicates where the definition of coupled TC-onset cases is made

5 Composites of $850-\mathrm{hPa} \mathbf{a} \chi$ and $\mathbf{b}, \Psi$ based on 27 post 1979 pre-monsoon cyclogenesis, applied with a 30-60 day bandpass filtering (contour interval: $0.31 .210^{6} \mathrm{~m}^{2} \mathrm{~s}^{-1}$ ). Vectors in a represent divergent winds while positive anomalies are shaded. Places marked with "L" in $\mathbf{b}$ show the center of the trough. The position of each TC at the time of genesis to 10 days after are also superimposed as red multiplication marks.

6 Horizontal maps showing differences in a VWS $(\mathrm{m} / \mathrm{s})$, b 30-60 days bandpassed $\Psi$ at $850-\mathrm{hP}\left(10^{6} \mathrm{~m}^{2} \mathrm{~s}^{-1}\right)$, c OLR $\left(W m^{-2}\right)$ and d SST $(\mathrm{K})$; between mean composites of a coupled cases, and b decoupled cases (coupled - decoupled). ENSO signal is removed from SST composites

7 EOFs of 30-60 days bandpassed $\chi$ at 850-hPa for a coupled TC-onset cases an b decoupled TC-onset cases, along with phase space from April through June, 
using PC1 and PC2. The black lines join centers of enhanced convergence. The red dots show the onset whiles the green dots show TC lifetime. Circles mark NIO.

8 Global SST regressed with BoB SST based on coupled TC-onset cases (i.e. a composite approach). Only years with pre-monsoon TC occurrences are used. The green box in the $\mathrm{BoB}$ outlines the domain used (longitude $80-97^{\circ} \mathrm{E}$ and latitude $5-20^{\circ} \mathrm{N}$ ). The grey mesh masks out insignificant areas (confidence interval $=95 \%$ )

9 Same as Fig. 8 but for decoupled TC-onset cases. Only years without premonsoon TC occurrences are used

10 Mean composites of $850-\mathrm{hPa} 30-60$ bandpassed $\chi$ based of a coupled TConset cases, $\mathbf{b}$ decoupled cases, and $\mathbf{c}$ difference between the two groups. The black parallel lines runs across the same region on the maps in each case .....27

11 Correlation maps of global SST with the BoB, along with EOFs extracted from the region boarded by longitude $80^{\circ} \mathrm{E}-97^{\circ} \mathrm{E}$ and latitude $20^{\circ} S-20^{\circ} \mathrm{N}$, between 1979 and 2010 using NCEP reanalysis data products 


\section{CHAPTER 1}

\section{INTRODUCTION}

The early onset of the South Asian summer monsoon (SASM) occurs in the Bay of Bengal $(\mathrm{BoB})$ during May, followed by the onset over the South China Sea, and then over India (e.g. Wu and Zhang 1998; Mao and Wu 2007). Together with the formation of the BoB monsoon trough (Fig. 1a), the seasonal warming of sea surface temperature (SST), which peaks in May, provides favorable conditions not only for rainfall but also for tropical cyclones (TCs) (Wang et al. 2013). In contrast to other tropical cyclone basins, the BoB has two distinct seasonal peaks in $\mathrm{TC}$ occurrence. The first $\mathrm{TC}$ season occurs in May before the SASM onset (pre-monsoon), and the second spans from October to November, after the monsoon (post-monsoon); this is shown in Fig. 1b. After the monsoon matures, prevailing low-level southwesterly winds and upper level easterly winds together create a strong vertical wind shear, prohibiting TC formation and development. As a result, tropical disturbances that form at the heart of the monsoon season (June-August) seldom develop into TCs; instead they form monsoon depressions (Yoon and Huang 2012).

Intraseasonal oscillations (ISOs) affect monsoon development and TC formation in the BoB. While key conditions necessary for TC formation such as high SST, low vertical shear and low-level vorticity (e.g. Gray 1979) are present in the BoB during the pre-monsoon season, TCs do not arise simply because these conditions are met (Riehl 1950; Bergeron 1954). Additional forcing such as ISO is needed to trigger tropical cyclogenesis (Emanuel 2003; Krishnamohan et al. 2012). As was pointed out by Kikuchi 
and Wang (2010), about $60 \%$ of TCs that form over the Indian Ocean do so in association with significant ISO events.

The Madden-Julian Oscillation (MJO) is the dominant component of intraseasonal oscillations observed in the global tropics (Madden and Julian 1971). Owing to its connection to these and other weather systems, the MJO affects global medium and extended range weather forecasts (e.g. Hendon et al. 1999). The MJO is characterized by large regions of both enhanced (i.e. positive phase) and suppressed (i.e. negative phase) convection, which propagates eastwards slowly $\left(\sim 5 \mathrm{~ms}^{-1}\right)$ through the portion of the Indian and Pacific oceans where the sea surface is warm, with a period of about 30 to 60 days. The MJO constantly interacts with the underlying ocean and influences many weather and climate systems (Zhang 2005). In the tropics, the MJO modifies the large-scale circulation anomalies conducive for TC development; this is the case in the BoB (Krishnamohan 2012; Kikuchi and Wang 2010). During the positive phase of the MJO (based upon convergence over the Indian Ocean-western Pacific region), synoptic conditions that are favorable for TC development are considerably enhanced (Maloney and Hartmann 2000; Bessafi and Wheeler 2006; Ho et al. 2006). From now we will refer to this ISO-TC relationship as the "ISO-TC connection."

The MJO also influences the onset and intensity of the SASM by modulating the distinctive monsoon lifecycle. In addition to the day-to-day fluctuations of weather with timescales of five to seven days, a characteristic feature of monsoon rainfall is prolonged spells of dry and wet conditions often lasting for two to three weeks. Extended periods of such monsoon inactivity are known as monsoon breaks, and have long been associated with ISOs (Ramamurthy 1969; Raghavan 1973). The dry and wet spells of active and 
break conditions represent intraseasonal variation of the monsoon with timescales longer than synoptic variability (1-10 days) but shorter than a season (Dakshinamurthy and Keshavamurthy 1976; Alexander et al. 1978). While the positive phase of the MJO (enhanced convection) affects both the timing and intensity of the SASM, the negative phase (suppressed convection) initiates breaks in the monsoon and can even prematurely end the monsoon (Waliser 2005; Wang 2006). Hereafter we refer to the MJO-onset relationship discussed above as the "ISO-Onset connection."

Even though SASM variability and TC development in the BoB have been studied, the mechanism by which the MJO modulates the monsoon onset and TC activity collectively has not been explored. In other words, the relationship between the aforementioned ISO-Onset and ISO-TC connections remains unclear - we refer to this as the "ISO-Onset-TC connection." In the following analyses, we show that certain (stronger) MJO events can provide unique conditions for pre-monsoon TCs in the BoB to shortly precede, or form concurrently with the monsoon onset, further enhancing rainfall in Myanmar. Although the $\mathrm{BoB}$ is the least active $\mathrm{TC}$ basin in the world, it has the tendency of generating some of the worlds deadliest TCs.

Myanmar is highly vulnerable to the impact of tropical cyclones that form in the BoB, as was exemplified by tropical cyclone Nargis in May 2008. According to the United Nations, tropical cyclone Nargis caused catastrophic destruction with at least 130,000 reported fatalities (Webster 2008; McPhaden et al. 2009) and an estimated $\$ 4$ billion in damages, making it the most destructive storm ever to hit the basin. But although destructive, tropical cyclones are important rain bearers. 
(a)

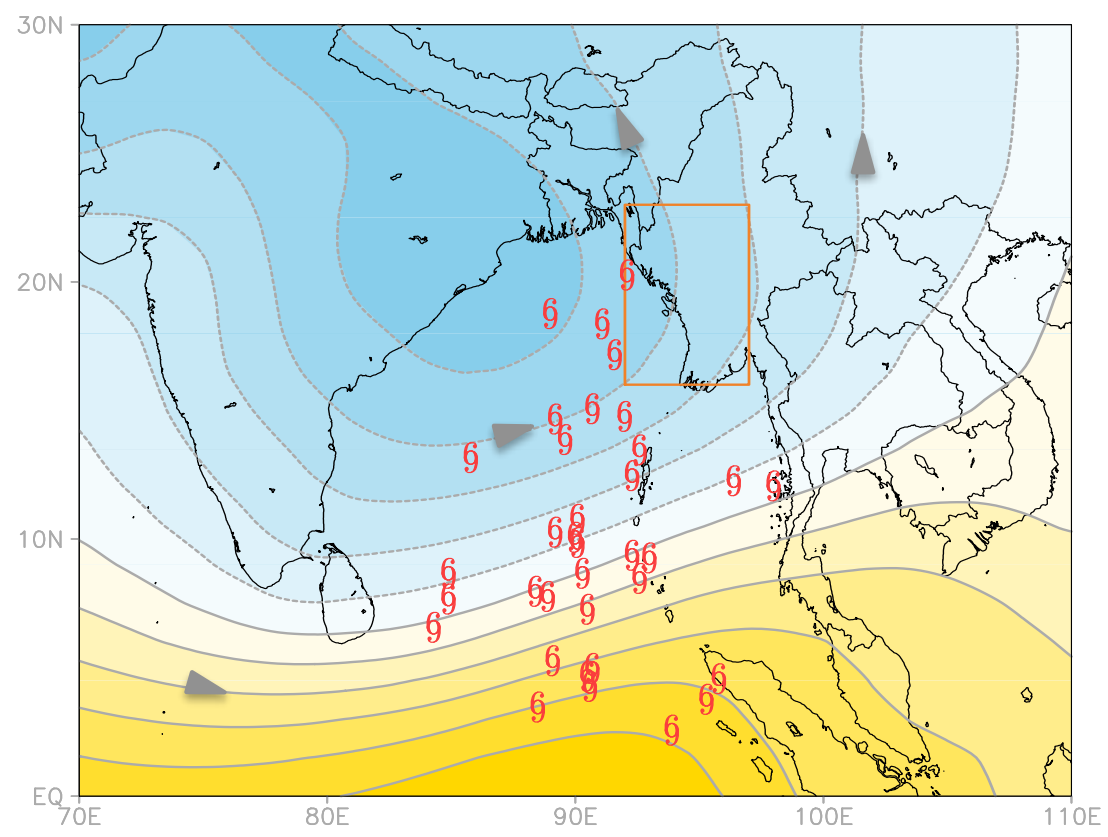

(b)

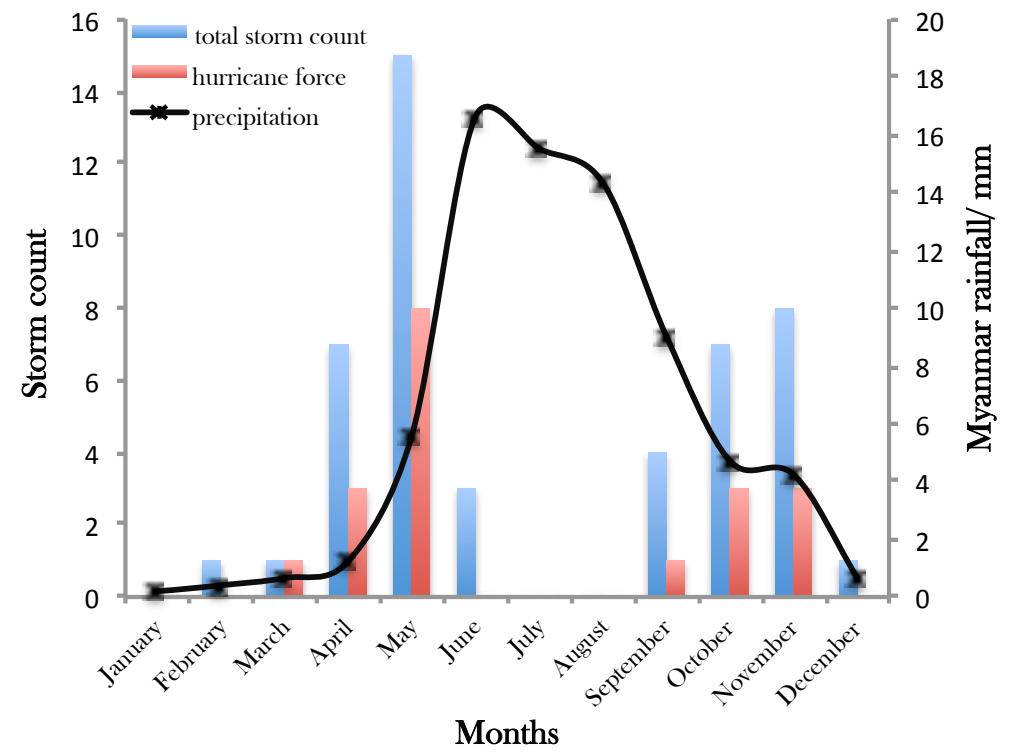

Fig. 1

a Mean 850-mb streamfunction ( $\Psi$ ) (contour interval: $1.2 \quad 10^{6} \mathrm{~m}^{2} \mathrm{~s}^{-1}$ ) of May, overlaid with all post 1979 spring cyclogenesis locations (red typhoon symbols ) in the BoB. b Tropical storm count in the BoB and rainfall distribution averaged from the orange box in a (western and central Myanmar). Hurricane force storms (red TC symbols) are cyclones with wind speeds greater than $107 \mathrm{~km} / \mathrm{h}$. 
The rainfall contribution of all pre-monsoon BoB storms to western and central Myanmar is shown in Fig. 1b. More than $22 \%$ of the world's population depends inextricably on the South Asian summer monsoon, which contributes as much as $75 \%$ of the total annual rainfall in major parts of the region (Dhar and Nandargi 2003). The substantial variability of onset and duration of the summer monsoon exerts a strong control on water resources, agriculture, economics, ecosystems, and human mortality throughout South Asia (Ashfaq et al. 2009). Having only recently opened to the western world after years of civil unrest and political instability, Myanmar employs $65 \%$ of its active labor force in agriculture, an industry that is heavily reliant on monsoon and TC rainfall. Furthermore, Wang et al (2013) have reported increased pre-monsoon TC activity in the BoB, characterized by stronger TCs with eastward-tending tracks. This change is attributed to increased anthropogenic aerosol loading in the atmosphere. Given the dependence of Burmese on monsoon rainfall and the negative TC impact in the region, the accurate prediction of the Myanmar monsoon onset, and its coupling with TCs as we hypothesize in this paper is an issue of both scientific and societal importance. Additional understanding of the ISOonset-TC connection could provide further insight into predicting the Myanmar monsoon onset and aid in disaster planning for TC impact.

The rest of the paper is organized as follows: chapter 2 briefly outlines the data used. In chapter 3, we introduce terminologies used throughout this study, and describe the analytical procedures utilized. Results portraying the MJO's influence on (a) BoB tropical cyclogeneses and on (b) the Myanmar monsoon onset concurrently are discussed in chapter 4 . Finally, a summary, and conclusions are provided in chapter 5. 


\section{CHAPTER 2}

\section{DATA SOURCES}

Four datasets were used in this study. The European Centre for Medium Range Forecasts reanalysis (Dee et al. 2011), available on a $1.5^{\circ}$ by $1.5^{\circ}$ latitude and longitude grid was used to compute streamfunction $(\Psi)$, velocity potential $(\chi)$, and vertical wind shear (VWS). For rainfall, the Asian Precipitation Highly-Resolved Observational Data Integration Towards Evaluation (APHRODITE) of Water Resources gridded precipitation dataset available on a $0.5^{\circ}$ grid (Yatagai et al. 2012), was analyzed from 1979 to 2010. Next, the National Center for Environmental Prediction (NCEP) sea surface temperature (SST) with a spatial resolution of about $1.875^{\circ}$ by $1.875^{\circ}$ (Kistler et al. 2001) was utilized, along with the NOAA outgoing longwave radiation (OLR) dataset. TC best track records were obtained from the Joint Typhoon Warning Center (JTWC) at their webpage http://www.usno.navy.mil/NOOC/nmfc-ph/RSS/jtwc/best_tracks. The JTWC website provides positional information on latitude and longitude, of the storm track, maximum sustained winds and central pressure; all at six-hour intervals. Tropical cyclone genesis day was defined when a disturbance was first classified as a tropical depression in the BoB. 


\section{CHAPTER 3}

\section{ANALYSIS PROCEDURES}

Here we provide a description of analytical methods used. Interpretation and discussion of the results are presented in chapter 4.

\subsection{Onset definition}

For the identification of yearly monsoon onset dates, we used western and central Myanmar $\left(16^{\circ}-23^{\circ} \mathrm{N}\right.$ and $\left.92^{\circ}-97^{\circ} \mathrm{E}\right)$ as the location, specified by the orange box in Fig. 1a. The monsoon onset in Myanmar varies with location. According to Htway and Matsumoto (2011), there are four climatological monsoon onset regions in Myanmar. These regions include but may not be limited to the Southern, Eastern, Western and Central, and Northern regions of Myanmar. When TC's make landfall, they die down as they suck dry air and move farther inwards. Moreover, most BoB TCs in the recent epoch have the tendency of tracking eastwards towards the Eastern Coast of the Indochina peninsula, where the first point of impact is Western Myanmar. Furthermore, the observed monsoon rainfall in Myanmar is most variable in the central part. This makes western and central Myanmar the region most vulnerable to tropical cyclone impact, and the region most susceptible to the effect of monsoon variability; hence our decision to limit our analysis to western and central Myanmar.

To define monsoon onset, various meteorological parameters have been used with mixed results; these include wind speed and direction (Matsumoto 1992), precipitation (Matsumoto 1997; Wang and Lin 2002), outgoing longwave radiation (Murakami and Matsumoto 1994) and cloud amount (Tanaka 1992). Among these parameters, rainfall is 
used operationally since its variation reflects the variability of the monsoon circulation system in general. The present definition of monsoon onset as used by the Myanmar Department of Meteorology and Hydrology is the first day of three consecutive rainy days with daily rainfall amount of $2.54 \mathrm{~mm}$ or more. Yet, it is not uncommon to have three days of significant rainfall resulting from propagating tropical disturbances that may be unrelated to the development of monsoonal winds. It was therefore imperative to isolate such "bogus" onsets.

Against this backdrop, and knowing the monsoon exhibits a strong seasonal variability, we defined a new onset selection scheme that could pick the yearly onset dates as representative as possible. First, we used the mean May precipitation to normalize daily precipitation data, after which a 5-days running mean was applied. Beginning April 1, the onset criteria was satisfied on any day from which the accumulated rainfall of the preceding 14 days was less than the accumulated rainfall of the following 14 days. This procedure is illustrated in Fig. 2 for every year since 1979. To ensure the difference between the two totals was substantial, as is expected to characterize monsoon onsets, the difference had to be greater than a third of the total May precipitation.

\subsection{Velocity potential and streamfunction representation of the MJO}

To illustrate the large-scale circulation patterns associated with the MJO and monsoonal flow, we used streamfunction $(\Psi)$ and velocity potential $(\chi)$ formulations. In lower latitudes, the geostrophic balance breaks down as the Coriolis parameter becomes small. Streamfunction and velocity potential therefore become more suitable scalar variables for depicting flow patterns than other traditional variables (Li et al. 2006), such 


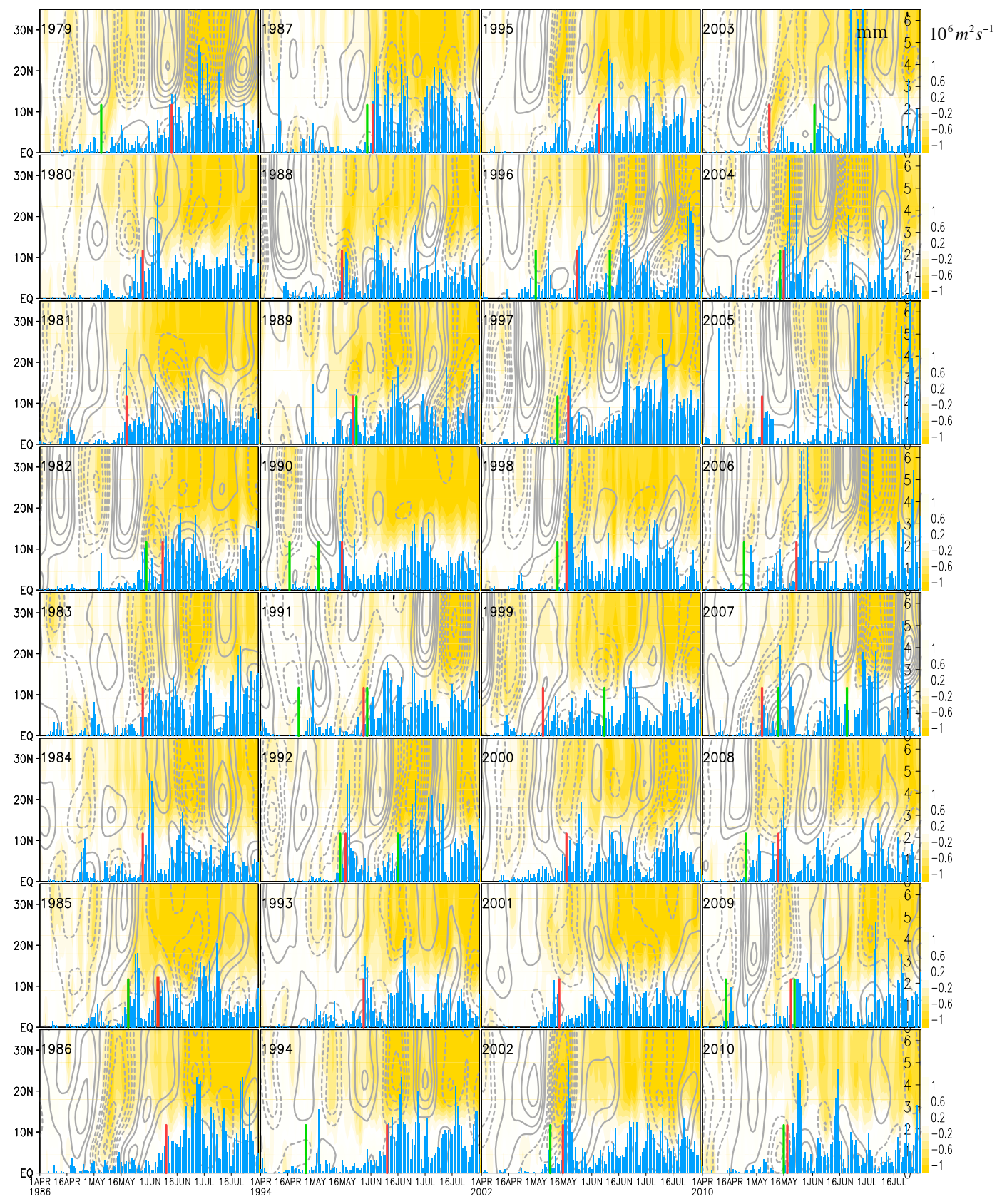

Fig. 2

850-hPa unfiltered $\Psi$ fields (shaded), superimposed with 30-60 days bandpassed $\Psi$ (contours, interval: $0.710^{6} \mathrm{~m}^{2} \mathrm{~s}^{-1}$ ) averaged over longitude 80-100 E. Histograms of daily precipitation from April through July over western and central Myanmar for each year is overlaid in blue. Red and green lines show onset and tropical cyclogenesis dates respectively. 
as pressure and geopotential height (Palmer 1952). Thus, $\Psi$ and $\chi$ are more suitable for analyzing flow patterns when spatial scales are smaller than the Rossby radius of deformation (Li et al. 2006). According to the Helmholtz theorem of vector calculus, and its mathematical formulation for two-dimensional fluid flow, on a simple domain, flow can be divided into a purely irrotational term and a non-divergent (solenoidal) term (Adames et al. 2013):

$$
\vec{u}=\nabla_{\chi}-\nabla \times(\mathrm{k} \psi)
$$

where $\chi$ is velocity potential and $\psi$ is the streamfunction. $\chi$ and $\psi$ are related to divergence (D) and vorticity $(\zeta)$, respectively, by the Laplacian operator $(\nabla)$ :

$$
\begin{aligned}
& \nabla_{s}^{2} \psi=\zeta \\
& \nabla_{s}^{2} \chi=D
\end{aligned}
$$

where $\nabla_{s}^{2}$ represents the two-dimensional Laplacian operator over the surface of the Earth (radius $\mathrm{a}=6,353 \mathrm{~km}$ ). The operator has the form:

$$
\nabla_{s}^{2}=\frac{1}{a^{2} \cos \phi} \frac{\partial}{\partial \phi}\left(\cos \frac{\partial}{\partial \phi}\right)+\frac{1}{a^{2} \sin ^{2} \phi} \frac{\partial^{2}}{\partial \lambda^{2}}
$$

where $\phi$ represents latitude and $\lambda$ represents longitude. An explicit solution for $\chi$ and $\psi$ has the form:

$$
\begin{aligned}
& \psi(\lambda, \phi)=\frac{1}{4 \pi} \int \zeta\left(\lambda^{\prime}, \phi^{\prime}\right) \ln (1-\cos \gamma) \mathrm{d} \Omega^{\prime} \\
& \chi(\lambda, \phi)=\frac{1}{4 \pi} \int D\left(\lambda^{\prime}, \phi^{\prime}\right) \ln (1-\cos \gamma) \mathrm{d} \Omega^{\prime}
\end{aligned}
$$

where $\gamma\left(\lambda, \lambda^{\prime}, \phi, \phi^{\prime}\right)$ is the central angle between two arbitrary points on the surface of the Earth (Fig. 3). Essentially, $\chi$ and $\psi$ describe the gravest planetary modes of vorticity and divergence, as the application of an inverse Laplacian acts as a spatial-smoother ope- 


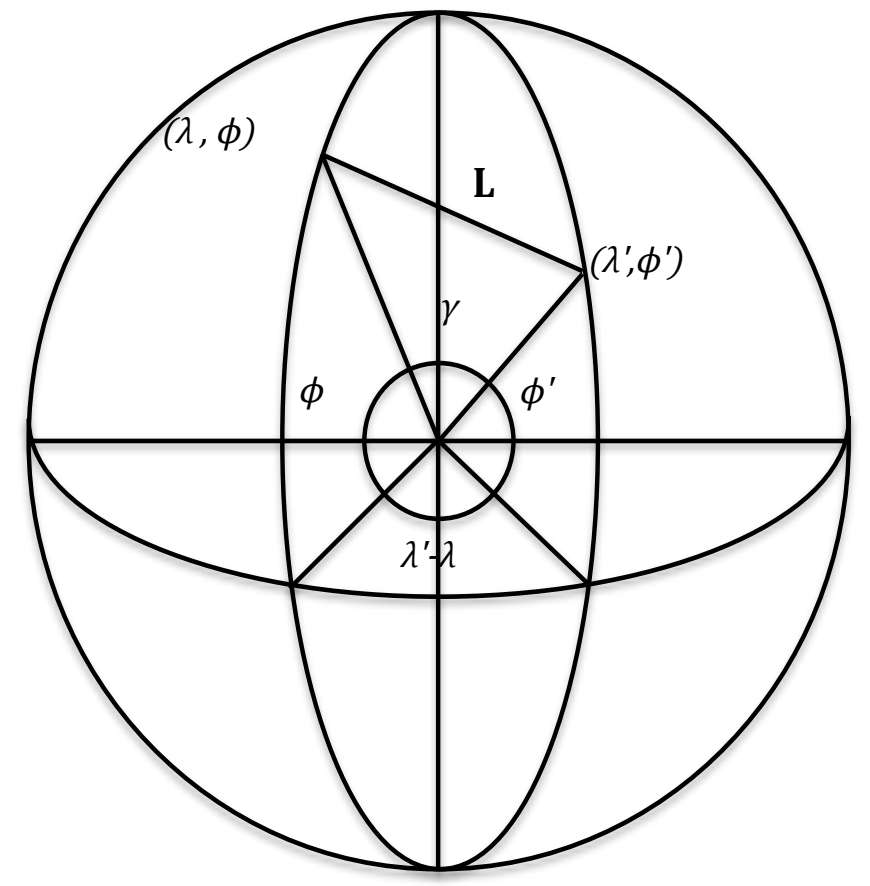

Fig. 3

Schematic showing the variables used in calculating velocity potential and streamfunction in the equations described in section 3.2. $\mathbf{L}$ is defined as the chord distance between the two points $(\lambda, \phi)$ and $\left(\lambda^{\prime}, \phi^{\prime}\right)$ 
rator (Hendon 1986; Geisler and Pitcher 1988). By keeping rotational (irrotational, $\psi$ ) flow constant (i.e. 0 ), we can analyze only the divergent (rotational, $\chi$ ) part of the flow. This property makes the two fields suitable for studying the MJO, which is characterized by its zonal wavenumber 1-3 kinematic structure. A schematic representation of variables used in calculating $\chi$ and $\psi$ is illustrated in Fig. 3 .

\subsection{Composite evolution of the monsoon, and TCs}

The remainder of this study will be based upon composites of the time evolution of rainfall and various atmospheric fields relative to monsoon onset dates in Myanmar and cyclogenesis dates over the BoB. Recently, the use of $\chi$ as a diagnostic tool for studying the MJO has received renewed attention. Chen and Del Genio (2008) developed an MJO index which was based on extended EOF analysis, applied to pentad-mean 200 $\mathrm{hPa} \chi$ anomalies. Ventrice et al (2013) developed a variant on the index originally developed by Wheeler and Hendon (2004) that uses velocity potential in place of OLR, which showed an improved representation of MJO related features over the western hemisphere. In this paper we computed $\chi$ and $\Psi$, and used them as the major variables in describing the global structure of the MJO with emphasis on the Indian Ocean -Western Pacific Ocean. Being interested in interactions between tropical convection and the MJO, the idea was to look at the evolution of weather states as a function of the MJO phase with time.

Using the selected onset dates, a composite evolution of monsoon rainfall was constructed based upon the Myanmar monsoon onset relative to every year. Unlike an evolution which is based on regular calendar days (i.e. daily climatology), the composite evolution of Myanmar rainfall as we demonstrate in Fig 4a starts with the addition of 
precipitation 60 days prior to each onset and continues 40 additional days after, resulting in a 101-days composite evolution. Day 0 is the average onset, or May 20 on average. Similar composites for streamfunction ( $\Psi$ ) at the 850 -hPa level are displayed in Fig. $4 \mathrm{~b}$, averaged over longitude $80-100^{\circ} \mathrm{E}$ for 1) unfiltered fields (shaded), and 2) 30-60 days band passed fields (contours) to isolate the MJO signal. This bandpass window captures most Northern Hemisphere summer MJO variability. For all of the fields, the seasonal mean was removed prior to compositing. Unfiltered anomalies composited for $\Psi$ were smoothened slightly for the sake of plotting clarity. Tropical cyclogenesis days were then superimposed relative to the composite onset, at the specific latitude of occurrence. The year-to-year computation of $\Psi$ is overlaid in Fig. 2 in comparison with each onset and TC occurrence.

Next, more composites of $\Psi$ and velocity potential $(\chi)$ were constructed, but here based on the dates of tropical cyclogenesis (Fig. 5). This was done to facilitate the depiction of the circulation features that promote TC genesis (Ventrice et al. 2013). In addition, onset based composites of $V W S, \chi, O L R$ and $S S T$ were also computed (Fig. 6). To explicitly depict the MJO influences as discussed earlier, a 30-60 day bandpass filter was applied on the various fields analyzed. 
(a)

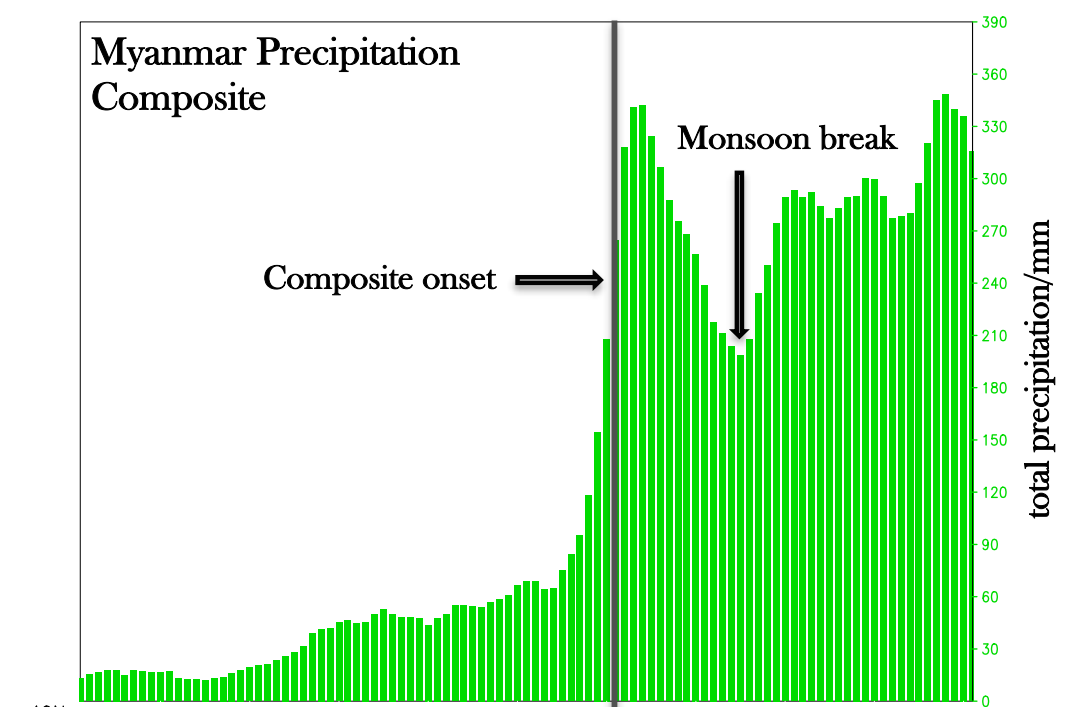

(b)

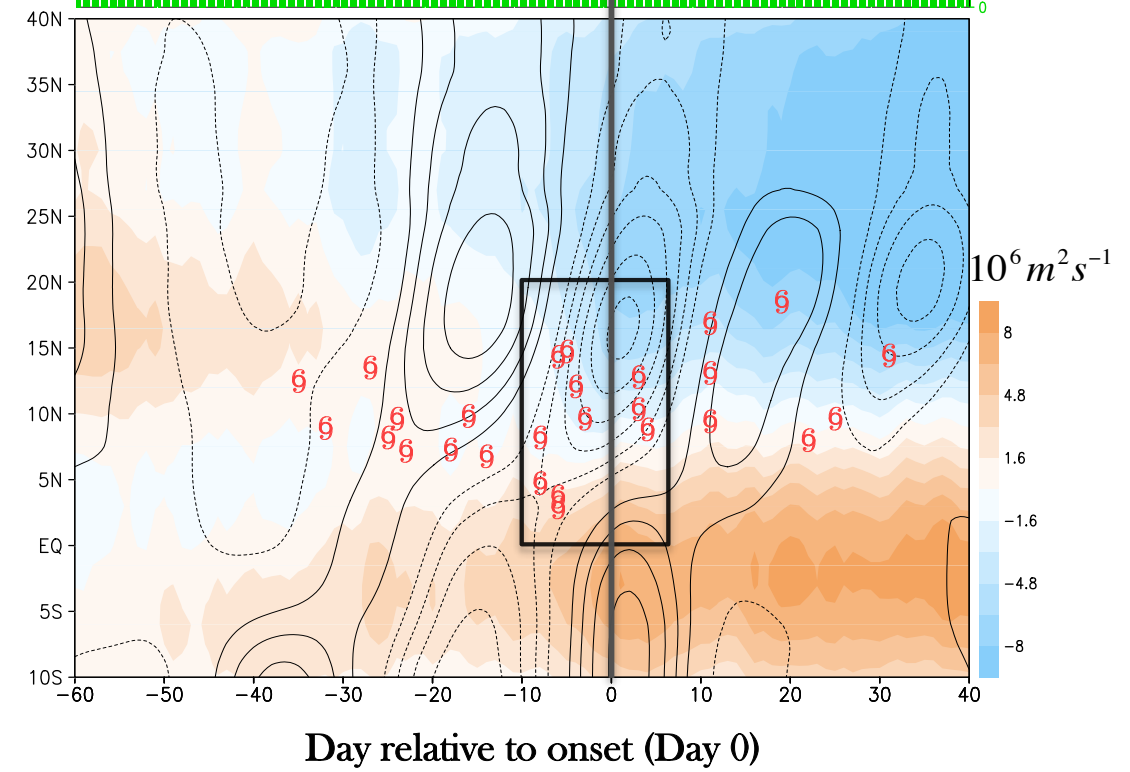

Fig. 4

a Composite evolution of daily rainfall averaged over western and central Myanmar. The average onset is May 20 (day 0, black line). b Composite evolution of 850-hPa unfiltered $\Psi$ fields (shaded), superimposed with 30-60 days bandpassed $\Psi$ (contours, interval: $1.610^{6} \mathrm{~m}^{2} \mathrm{~s}^{-1}$ ), averaged over longitude 80-100 E with the locations of all pre-monsoon tropical cyclogenesis (red TC symbols) superimposed. Cyclogenesis days are plotted relative to the composite onset, at the same latitude they occurred. The black box indicates where the definition of coupled TC-onset cases is made. 
(a)
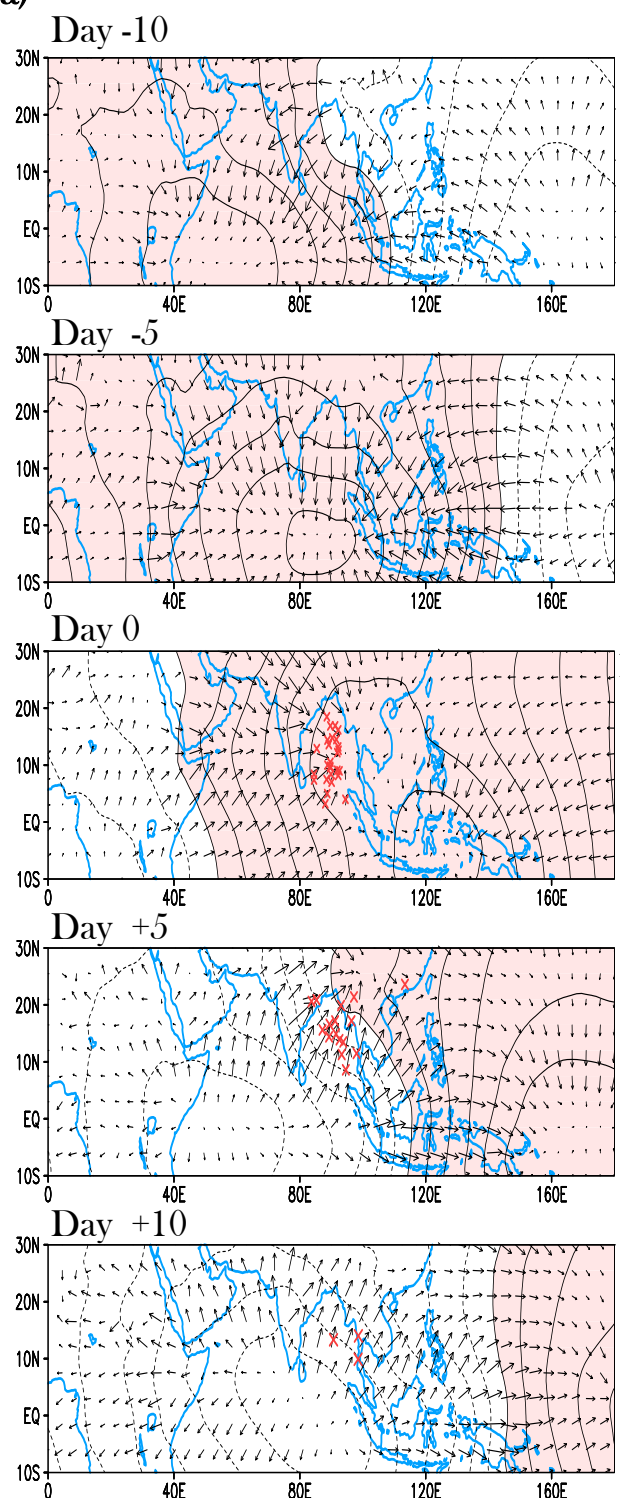

(b)
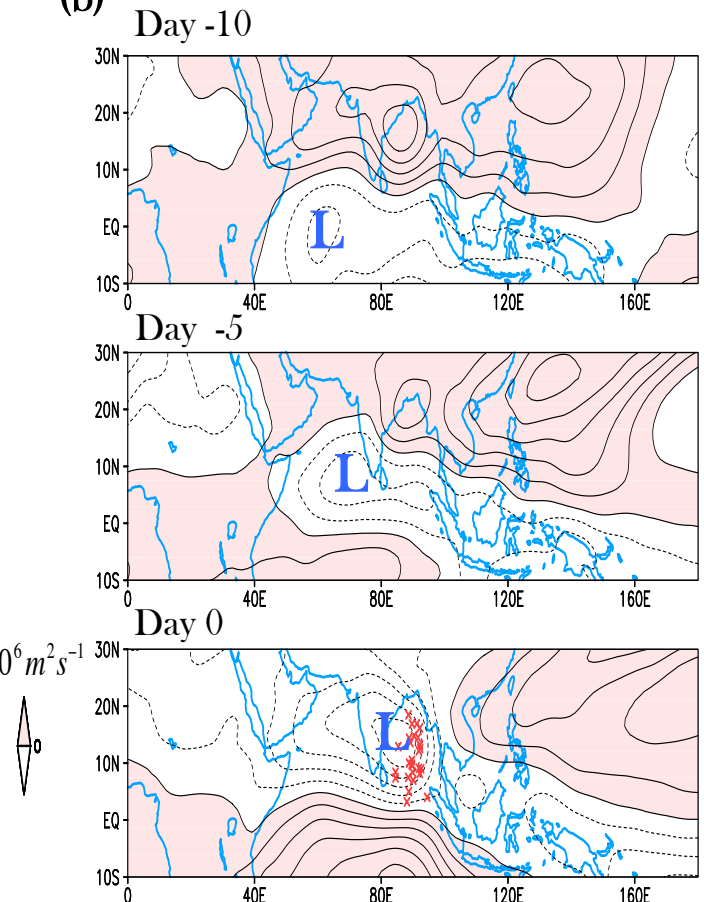

$10^{6} \mathrm{~m}^{2} \mathrm{~s}^{-1}$
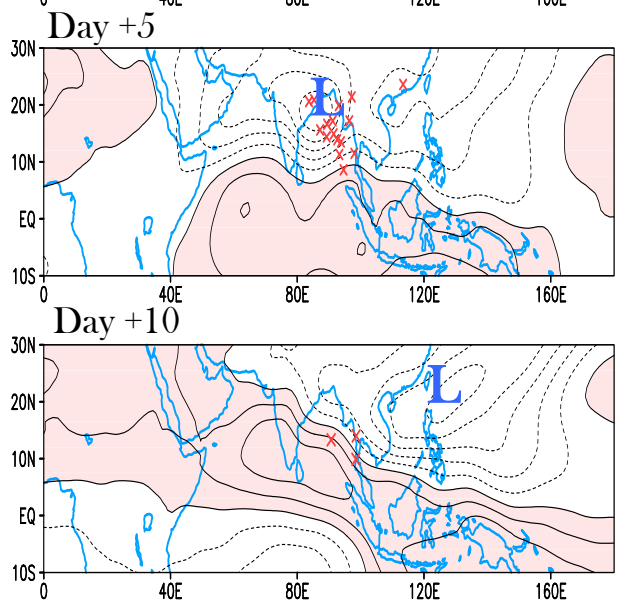

Fig. 5

Composites $850-\mathrm{hPa}$ a $\chi$ and $\mathbf{b} \Psi$ based on 27 post 1979 pre-monsoon cyclogenesis, applied with a 30-60 day bandpass filtering (contour interval: $0.310^{6} \mathrm{~m}^{2} \mathrm{~s}^{-1}$ ). Vectors in a represent divergent winds while positive anomalies are shaded. Places marked with " $\mathbf{L}$ " in $\mathbf{b}$ show the center of the trough. The position of each TC at the time of genesis to 10 days after are also superimposed using red multiplication marks. 
(a) SHEAR

(b) ST 850

(c) OLR

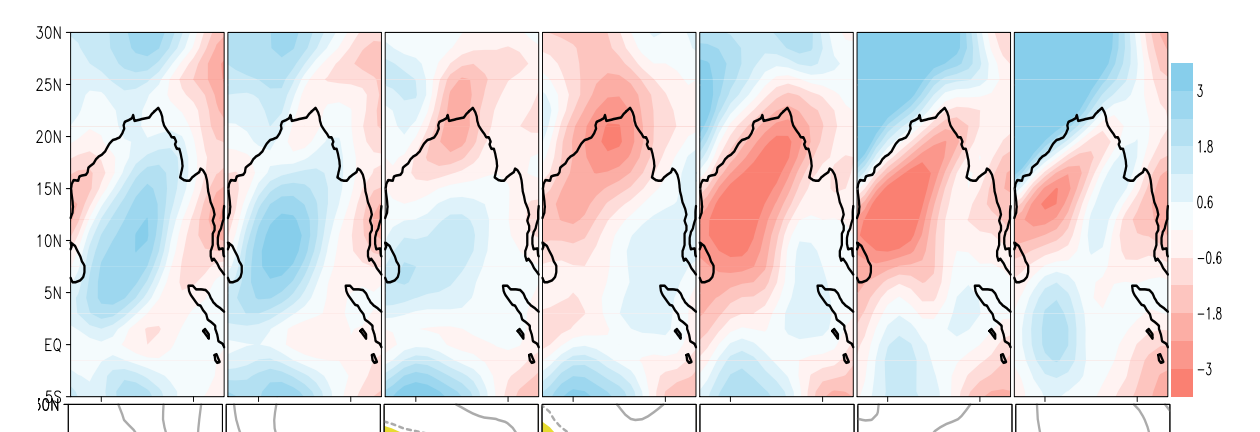

(d) SST

Day -15 Day -10 Day -5 Onset Day +5 Day +10 Day +15 


\subsection{EOF representation of the $M J O$}

Climate variations are the results of exceedingly complex nonlinear interactions between very many modes, characterized by nonlinearity and high dimensionality. Consequently, a challenging task is to find ways to reduce the dimensionality of climate systems and find the important patterns explaining their variations. Whiles several researchers have used different methods in extracting important patterns from atmospheric variables; the Empirical Orthogonal Function (EOF) (Obukhov 1947, 1960; Lorenz 1956) technique has become the most widely applied. An index time series known as Principal Components (PCs) is generated; derived from a statistical procedure that uses the orthogonal transformation to convert a set of observations of possibly correlated variables into a set of values of linearly uncorrelated variables. The simplicity and the analytic derivation of EOF are the main reasons behind its popularity in atmospheric science. In recent times, individual modes of variability such as the Artic Oscillation (AO) (Thompson and Wallace 2000) and the Pacific Decadal Oscillation (PDO) (Mantua et al. 1997; Zhang et al. 1997) have been extracted using EOF techniques. EOFs are used for MJO representation, and SST tests in this study.

EOF analyses have been widely used in many studies to identify the MJO and its characteristics (Matthews 2000; Higgins and Shi 2000; Kessler 2001; Lo and Hendon 2000). Phase-space diagrams derived from Empirical Orthogonal Functions (EOFs) as described in Wheeler and Hendon (2004) can characterize the MJO's propagation and intensity with merely two parameters - phase and amplitude. A similar approach was used in this study as shown in Fig. 7. 
(a) Coupled TC-Onsets

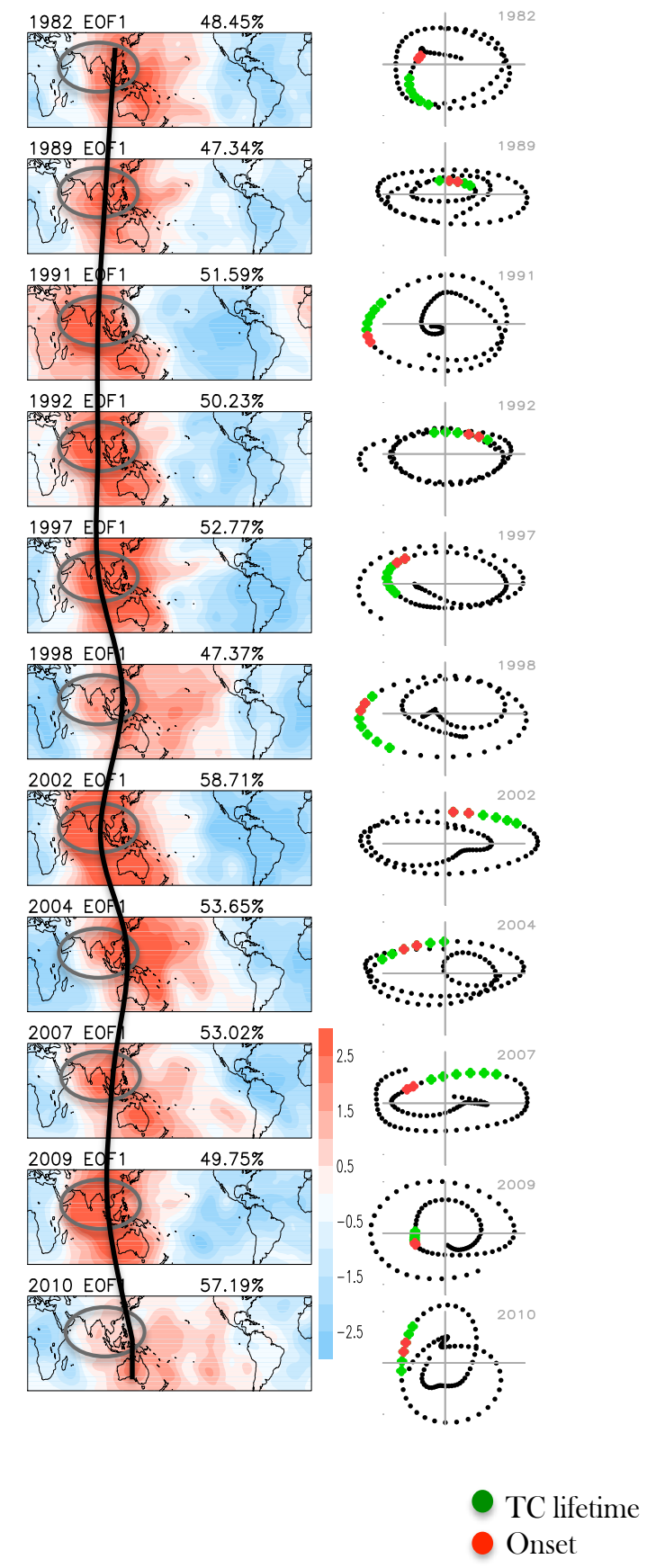

(b) Decoupled TC-Onsets

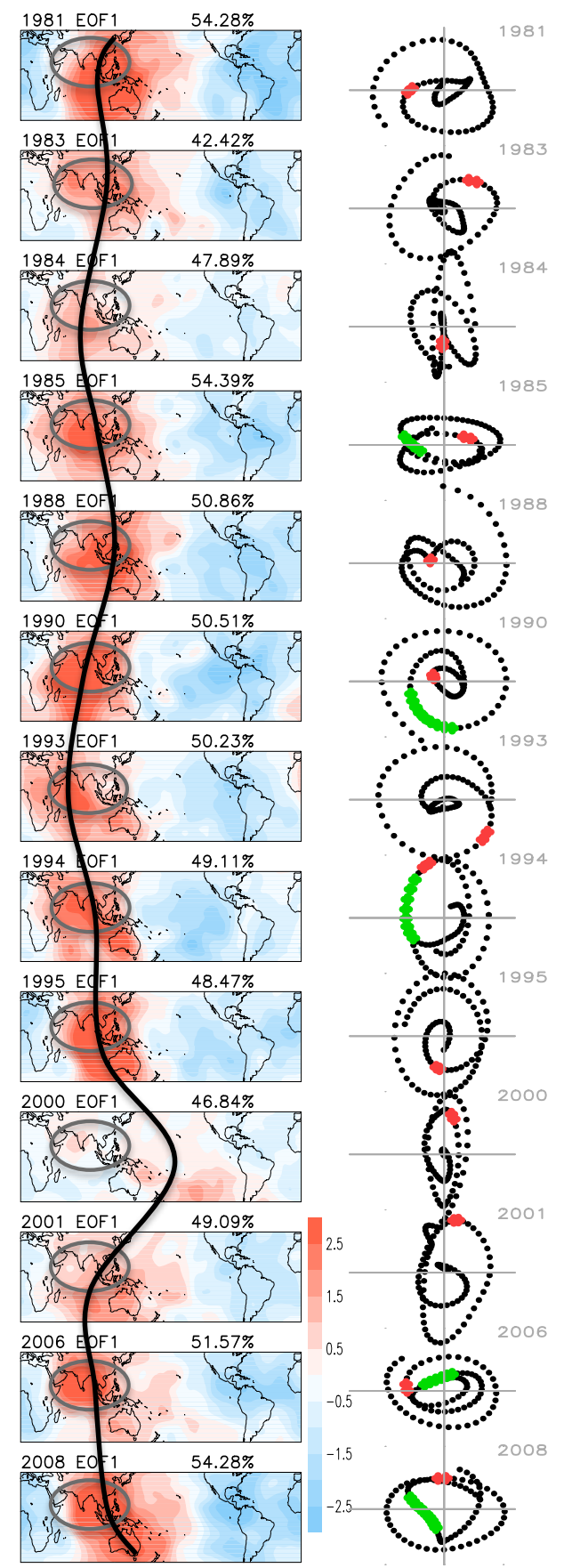

Fig. 7

EOFs of 30-60 days bandpassed $\chi$ at $850-\mathrm{hPa}$ for a coupled TC-onset cases and $\mathbf{b}$ decoupled TC-onset cases, along with phase space from April through June, using PC1 and PC2. The black lines join centers of enhanced convergence. The red dots show the onset whiles the green dots show TC lifetime. Circles mark NIO. 
Several studies have used EOFs of single tropically confined fields that have been bandpass filtered to intraseasonal periods to identify the MJO (e.g. Maloney and Hartmann 1998; Slingo et al. 1999; Matthews 2000; Kessler 2001). The first measure of the MJO as we used here was based on bandpass filtered global velocity potential anomalies at 850-hPa. EOFs of bandpassed daily fields were computed from Apr 1 through June 30, and the principal components (PCs) were used to construct phase-space diagrams (Fig. 7). The combination of the first two EOF's represents a half life cycle of the MJO, so when taken as a pair, the two PCs describe the global eastward-propagating signal attributed to the MJO. In order to gauge the strength of the MJO at any time, the PCs were normalized with their variances during the warm season. The EOFs then exhibit two distinctive circulations signatures - the positive (wet) and negative (dry) phase. The positive phase of the MJO enhances rising motion and induces lower tropospheric convergence in the Indian Ocean-Western Pacific, whiles the negative phase suppresses rising motion.

\subsection{Regression analyses}

Regression analysis is a vitally important statistical tool, with major advancements made by both practical data analysts and statistical theorists. When we examine the relationship between a quantitative outcome and a single quantitative explanatory variable, simple linear regression is the most commonly considered method. We postulate a linear relationship between the population mean of the outcome and the value of the explanatory variable. If we let $\mathrm{Y}$ be some outcome, and $x$ is some explanatory variable, then we can express the structural model using the equation:

$$
E(Y \mid x)=\beta_{o}+\beta_{1} x
$$


where the expected value, $\mathrm{E}(Y \mid x)$, indicates a population mean. $Y \mid x$ (i.e. Y given $x$ ) means that we are looking at the possible values of $\mathrm{Y}$ when $x$ is restricted to some single value; $\beta_{o}$ is the intercept parameter; and $\beta_{1}$ is the slope parameter.

Using linear regression, the ENSO signal was removed from SST anomalies by subtracting from each grid point the regression coefficient of Niño 3.4 with SST from 1979 to 2010 (Fig. 6d). A regression model was again used to illustrate the statistical relationship between SST variations in the BoB (green boxes in Figs. 8 and 9) and ENSO. We analyzed the mean response of BoB SST according to the magnitude and intervention of ENSO (Figs. 8 and 9). However, our regression analyses were not done year-round but for two seasons: 1) December-January-February (DJF) and 2) MarchApril-May (MAM). Whiles MAM is the pre-monsoon TC season in the BoB with SST peaking in May, the effect of the El Nino Southern Oscillation on the Northern Hemisphere is strongest during winter (DJF), as ocean temperatures worldwide are at their warmest. DJF is also the precursor to May SST, making it an important season to consider when looking ahead into the summer season. 

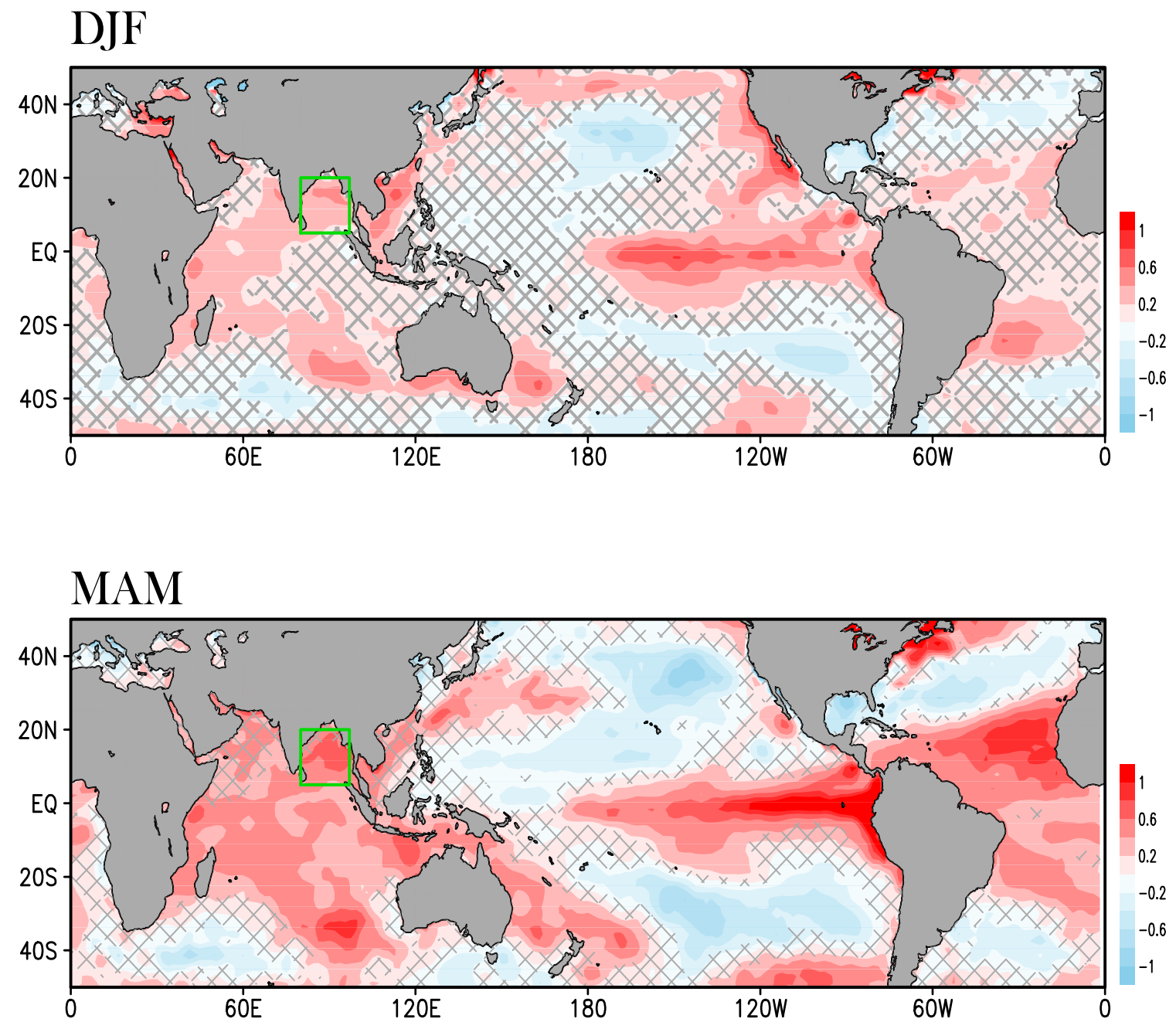

\section{Fig. 8}

Global SST regressed with BoB SST based on coupled TC-onset cases (i.e. a composite approach). Only coupled years are used. The green box in the $\mathrm{BoB}$ outlines the domain used (longitude $80-97^{\circ} \mathrm{E}$ and latitude $5-20^{\circ} \mathrm{N}$ ). The grey mesh masks out insignificant areas (confidence interval $=95 \%$ ). 

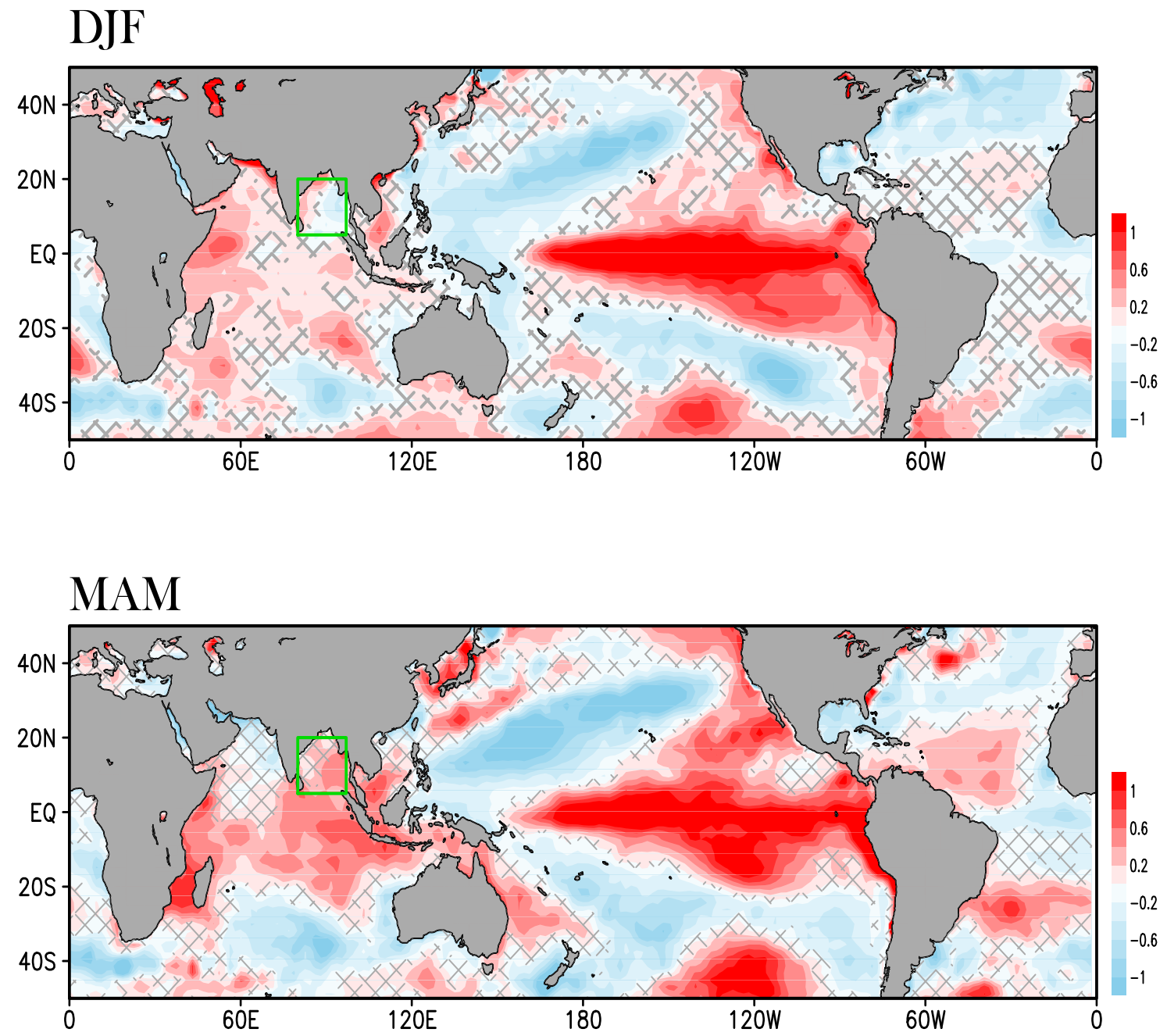

Fig. 9

Same as Fig. 8 but for decoupled TC-onset cases. Only decoupled years are used. 


\section{CHAPTER 4}

\section{RESULTS AND DISCUSSION}

\subsection{ISO-Onset connection}

To explain the aforementioned, "ISO-onset-TC connection" divulged in this study, we first needed to establish the relationship between the MJO and the Myanmar monsoon onset, i.e. the ISO-onset connection. Using methods outlined in chapter 3 , the composite evolution of the Myanmar monsoon rainfall is presented in Fig. 4a. Precipitation is persistently weak before the onset (day -60) until day 0 (or May 20) when an abrupt increase in rainfall occurs. About 15 days after the onset, a substantial decline in rainfall is observed (monsoon break). A comparison of the rainfall evolution with the latitude-time cross section of $850-\mathrm{hPa}$ streamfunction $(\Psi)$ anomalies (Fig. 4b) suggests the Myanmar monsoon onset (break) occurs during the positive (negative) phase of the $\mathrm{MJO}$, represented by cyclonic (anticyclonic) circulation anomalies. This feature is consistent with the well-known northward migration of the 30-60 days mode and its modulation of the Indian summer monsoon. We also note that the composite monsoon break as shown in Fig. 4a occurs within the negative phase of the MJO (Fig. 4b). It appears unfavorable conditions associated with this phase of the MJO may be an influencing factor in suppressing rainfall.

\subsection{ISO-TC connection}

Next, we investigated how the MJO influences TC formation and development in the $\mathrm{BoB}$, i.e. the ISO-TC connection. The relationship between cyclogenesis and MJO evolution can be observed in Fig. 4b, where a majority of TCs occur within the MJO- 
enhanced monsoon trough. Furthermore, plots of TC genesis-based composites of the horizontal distribution of $\chi$ (Fig. 5a) and $\Psi$ (Fig. 5b) demonstrate how the MJO's migration relates to TC activity. The positions of each TC at the time of genesis (Day 0) and after (Day +5 and Day +10$)$ are shown. As seen in Fig. 5a, ten days before a TC genesis (Day -10), anomalous convergence associated with the MJO (positive phase) develops over the equatorial Western Indian Ocean. After five days (Day -5), the area of convergence shifts to India and the Indochina Peninsula. By the day of TC genesis (Day 0 ), the area of convergence exits India and moves farther east, centered over the Maritime continent. Five days after genesis, the MJO associated convergence crosses the maritime continent into the Western Pacific (Day +5$)$, and travels farther east into the Eastern Pacific by the tenth day (Day +10$)$. In terms of rotational flows (Fig. 5b), areas of cyclonic rotation (positive MJO phase) occur behind areas of convergence as the MJO propagates eastwards, following a Gill-type dynamics. It is interesting but not surprising that TC genesis (Day 0) occurs with the strongest MJO trough in the BoB.

\subsection{ISO-Onset-TC connection}

The results so far have illustrated the ISO-onset (Fig. 4) and ISO-TC (Fig. 5) connections. However, as was found in Fig. 4b, only 11 of the 27 pre-monsoon cyclogenesis occurred during or near the time of onset; this discrepancy suggests that, for the monsoon onset and TC genesis to occur concurrently (ISO-onset-TC connection), additional environmental factors must be at play. To proceed, we first needed to define TC-onset coupling: A "coupled" onset was defined as one that occurred within 10 days (10 days before or after) of cyclogenesis in the BoB. There are 11 of such cases as outlined by the black box in Fig. 4b, and these are referred to as "coupled TC-onset" 
cases. The rest of the onsets or TCs are considered "decoupled" cases. Since this paper targets the Onset-ISO-TC connection, we limited the "decoupled" cases to only onsets that occurred within the positive phase of the MJO, without a TC occurrence within 10 days (or none at all). There are 13 such cases.

Next, the amplitude and phasing of the MJO are examined through EOF analysis. Shown in Fig. $7 \mathrm{a}$ are the EOF1 patterns and their corresponding phase space diagrams for coupled TC-onset cases (in terms of years), along with similar plots for decoupled TConset cases (Fig. 7b). The coupled cases generally boast stronger convergence/divergence patterns in EOF1 when compared to the decoupled cases - this means the Indian OceanWestern Pacific "mode" of MJO is strong. For ease of comparison, we add a black line that traces the center of convergence throughout all panels in the column. The line of track in Fig. 7a is clearly "straighter" than that in Fig. 7b, suggesting that the convergence center over the Indian Ocean-Western Pacific is more systematic and pronounced in the coupled cases, suggesting stronger MJO convergence during coupled TC-onsets, as opposed to decoupled events.

The shapes of the two sets of phase space diagrams are also noticeably different, indicating a difference in the phasing and propagation of the MJO. While many of the sequential days trace anti-clockwise in eclipsed circles around the origin in the coupled cases (meaning EOF1 is distinctively stronger than EOF2), phase space diagrams of the decoupled cases appear as round shaped circles ensuing from random motions of sequential days around the origin. Thus the coupled cases feature a strong MJO cycle. On the contrary, the decoupled cases have rounder circles resulting from relatively smaller EOF1. The red dots reflect the time along the MJO cycle when the onset occurred, whiles 
the green dots show the TC initiation and lifetime. In the coupled cases, monsoon onsets consistently occur during distinct MJO episodes, while in the decoupled cases, onsets mostly take place in weak MJO phases.

\subsection{MJO phase, magnitude and amplitude}

To explore further the TC-onset connection, we construct onset-based $\chi$ composites, which are presented in Fig. 10a for the coupled cases and Fig. 10b for the decoupled cases. To facilitate comparison, a black parallel diagonal line is drawn connecting regions of maximum convergence to illustrate the MJO propagation for the coupled cases, shown in Fig. 10a; this line is then copied over to Figs. 10b and 10c. The difference between the phase and magnitude of the two groups is shown in Fig. 10c indicating strong low-level convergence over the BoB 15 days prior to $\mathrm{TC}$ genesis, arguably pooling moisture and generating heat. There is seemingly a quarter-cycle phase difference between coupled and decoupled cases; this could mean that either the phase or the propagation speed is consistently different between the two cases. Such year-to-year differences in the phase and magnitude of the MJO may explain why the formation of BoB TCs is coupled with the Myanmar monsoon onset in some years but not in other years. 
(a) Coupled

(b) Decoupled

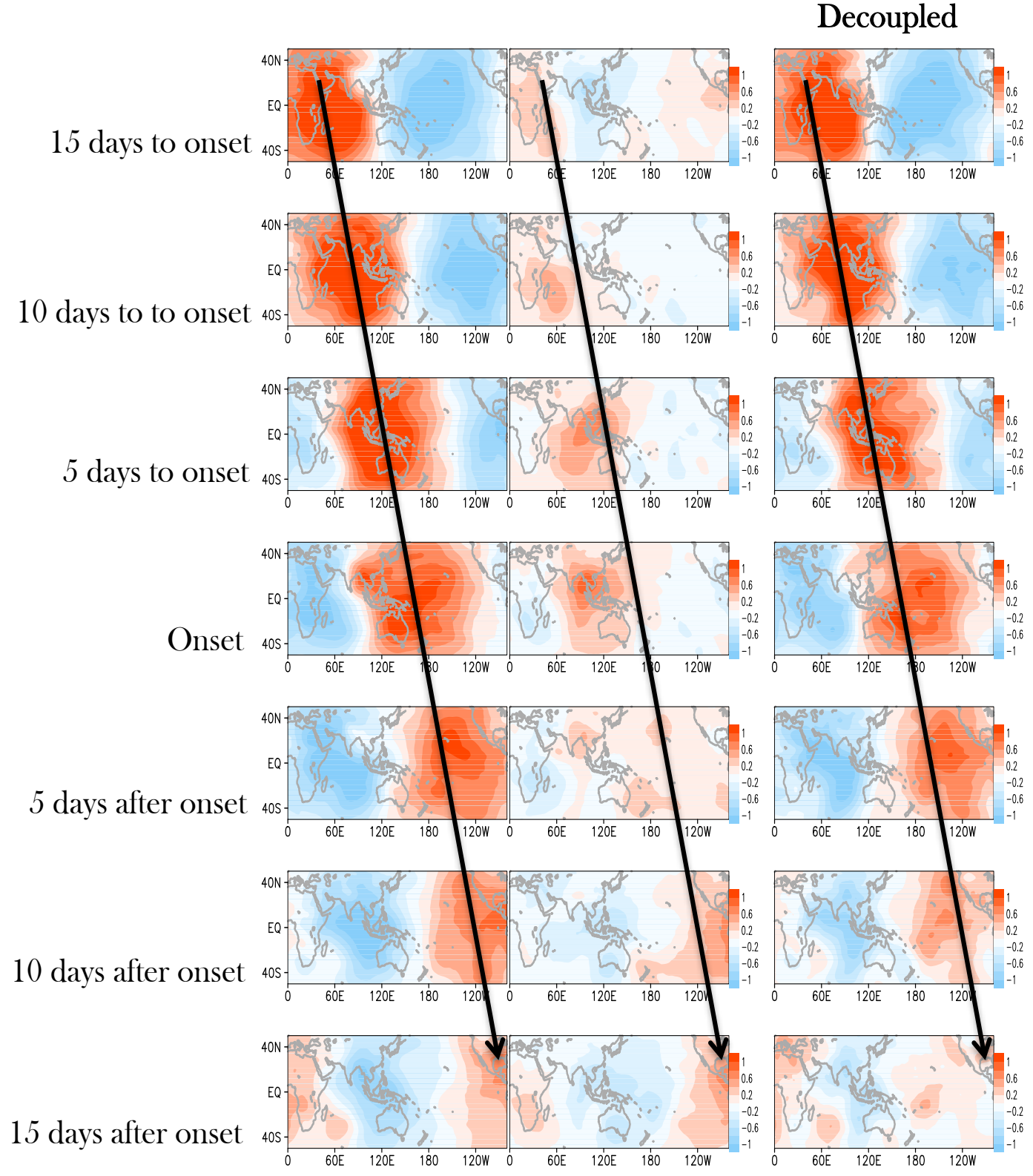

Fig. 10

Mean composites of 850-hPa 30-60 bandpassed $\chi$ based on a coupled TC-onset cases, $\mathbf{b}$ decoupled cases, and $\mathbf{c}$ difference between the two groups. The black parallel lines runs across the same region on the maps in each case. 


\subsection{Synoptic Conditions}

The synoptic conditions influencing onsets and $\mathrm{TC}$ geneses in the $\mathrm{BoB}$ are examined in Fig. 6, which shows the differences (coupled - decoupled) in the composite vertical wind shear (VWS), streamfunction $(\Psi)$, outgoing longwave radiation (OLR) and SST. Prior to the coupled onsets, vertical wind shear is relatively weak (Fig. 6a). Likewise, the BoB monsoon trough deepens (Fig. 6b) and surface convection intensifies (Fig. 6c), forming conditions conducive for $\mathrm{TC}$ formation. Within the low-level convergence phase of the MJO, equatorial westerlies intensify and subsequently enhance cyclonic circulation over the BoB (Fig. 6b). Meanwhile, an upper-level anticyclone develops (not shown) resulting in a reduction in vertical wind shear, which is favorable for TC development (Gray 1968; Zehr 1992; DeMaria and Kaplan 1999). After the monsoon onset, VWS increases and an anticyclone anomaly moves from the equator replacing the cyclonic anomaly, suppressing convection while creating unfavorable conditions for $\mathrm{TC}$ formation over the $\mathrm{BoB}$. The timescale of these variations are reminiscent of the MJO as well as its modulation on TC activity.

Also noteworthy is the SST variation associated with the TC-onset coupling, as is shown in Fig. 6d. Warmer waters develop prior to and during the onset (and TC genesis). This means increased energy fluxes towards the development of the monsoon trough that favors TC formation. Although the SST variation hints of an MJO modulation, SST in the BoB always maintains a critical temperature of above $27^{\circ} \mathrm{C}$ that is needed for tropical cyclogenesis. Further SST warming in the BoB creates feedbacks with evaporation and convection (Fig. 6c) while enhancing low-level convergence as seen in Fig. 5a. This leads to destabilization of the lower troposphere resulting in a rapid intensification of the BoB 
monsoon trough. Yet, there is an apparent SST cooling after the onset, presumably due to the post-onset and/or TC rainfall that cool the ocean surface.

\subsection{SST Variability}

The observed intraseasonal variation in SST is an intriguing feature. Previous studies have shown that intraseasonal SST variations do provide MJO feedback and vice versa (Wang and Xie 1998; Waliser et al. 1999). Using the regression methods described in section 3.5, we examine the relationship between BoB SST (green boxes in Figs. 8 and 9) and global SST through a composite approach. We analyze the winter (DJF) and premonsoon (MAM) seasons for: 1) years in which the onset and TCs were coupled (Fig. 8) and 2) years in which the onset and TCs were not coupled (Fig. 9). For coupled cases, there is a discernable but rather weak ENSO signal in both seasons, while the BoB SST is consistently warmer (Fig. 8). However, for decoupled cases (Fig. 9) the BoB SST is cooler and yet the ENSO signal is robust. Given the removal of the ENSO signal, and our earlier analysis showing that a stronger MJO and warmer SST favors the coupled cases, the results from Figs. 8 and 9 suggest that the MJO tends to be stronger in the Indian Ocean-Western Pacific during moderate ENSO events and weaker during strong ENSO events. This finding is consistent with the observations by Hendon et al (1998) that the overall level of MJO activity is found to be uncorrelated with El Nino except during exceptionally warm ENSO events by which the MJO is suppressed.

A further analysis of the BoB SST using EOF (Fig. 11) reveals that, while EOF2 produces an SST pattern resembling that in the coupled TC-onset cases (Fig. 6d), it only explained $17 \%$ of the variance. Correlation of PC 2 with global SST suggests that there is no significant El Nino influence (Fig. 11). It is therefore inferred that the subseasonal 
variability in SST revealed from Fig. 6d is only a response to the MJO's propagation, implying much of the yearly MJO variability may be internally generated.

\section{EOF one}
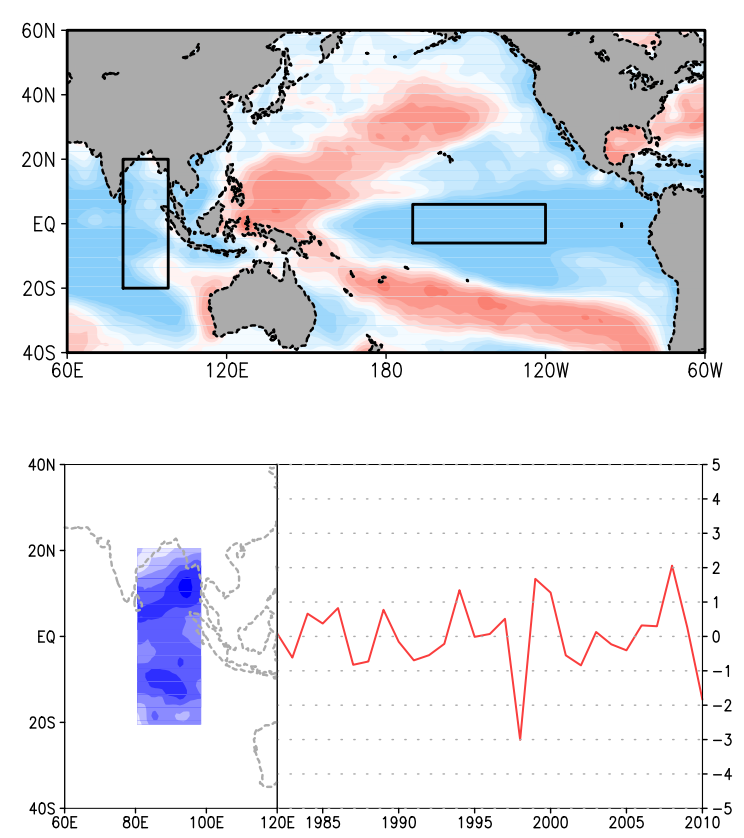

EOF two
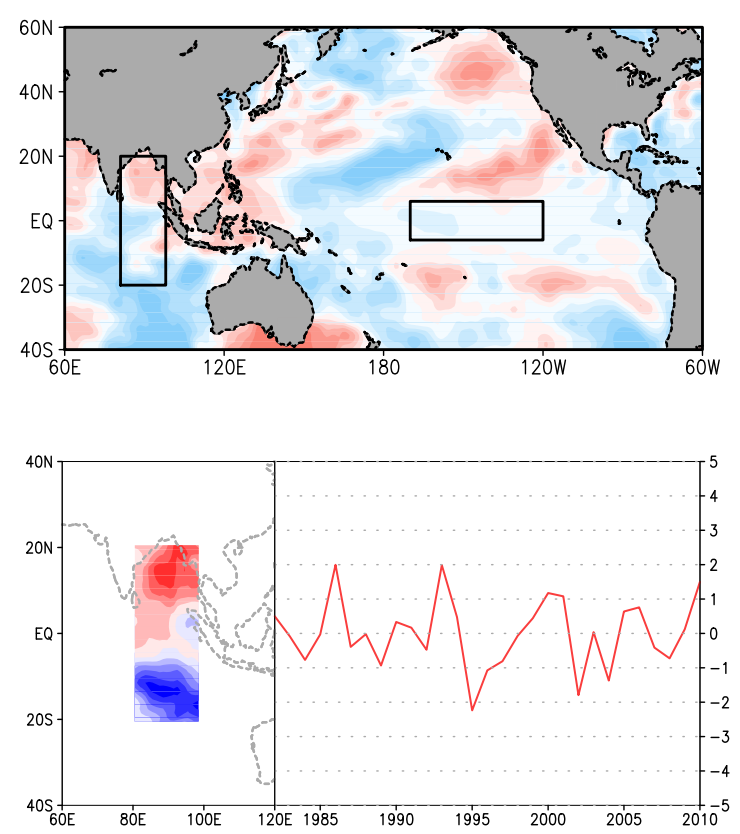

Fig. 11

Correlation maps of global SST with BoB, along with EOFs extracted from the region boarded by longitude $80 E-97 E$ and latitude $20 S-20 N$, from 1979 to 2010 , using NCEP reanalysis data products 


\section{CHAPTER 5}

\section{CONCLUDING REMARKS}

We have examined the extent to which the MJO modulates springtime TCs in the $\mathrm{BoB}$, the Myanmar monsoon onset, and eventually how the two are coupled in certain ways. The monsoon tends to initiate during the positive phase of the MJO (trough in the BoB) while the monsoon break occurs during the negative phase (ridge in the BoB). TCs in the $\mathrm{BoB}$ also preferentially occur during the positive phase of the MJO. When the MJO's positive phase coincides with the seasonal development of the monsoon trough during strong MJO activity seasons, TC genesis and monsoon onset are likely to occur concurrently. The MJO activity exhibits a marked interannual variability, which can be explained by a combination of magnitude and phasing, from which the concurrence of TC geneses and monsoon onsets are controlled. Given the relative strengths of MJO events in both coupled and decoupled cases, and how sensitive cyclogeneses are to environmental conditions, it seems plausible to say that it is the phasing of the MJO that more predominantly modulates the coupling. As the low-level convergence of the MJO propagates through the $\mathrm{BoB}$, the cyclonic anomaly develops and leads to a rapid intensification of westerlies and influx of moisture into the BoB. This leads to the intensification of the $\mathrm{BoB}$ monsoon trough. In the meantime, vertical wind shear is reduced, thus providing a favorable environment for TCs to form.

The SST in the BoB reaches its seasonal maximum around $30^{\circ}$ in spring. The warm SST amplifies the MJO modulation on TC geneses through feedbacks of evaporation and convection, and provides moisture for sustaining convection. The BoB SST anomaly was not found to link significantly with the interannual variability of the 
MJO. However, we did find that the MJO tends to intensify during weak/moderate El Nino events, and weaken during strong El Nino events.

Early forecasting techniques of the monsoon were essentially empirical. However dynamical predictions of the Asian summer monsoon have advanced significantly in recent decades, with a transition to a reliance of numerical techniques. Meanwhile, our ability to predict monsoon onset and variability has not substantially changed over the last few decades (Wang 2006). Many monsoon prediction and forecasting schemes use measures of the ENSO as major predictors of monsoon variability (e.gs Shukla and Paolina 1983; Rasmussen and Carpenter 1983). Whereas there are periods of extremely high association between the ENSO and monsoon variability, there are decades where there appears to be little or no association at all (Torrence and Webster 1999). Recent studies that analyzed retrospective predictions of the NCEP Climate Forecast System have indicated that the model could simulate the broad structure of the Asian monsoon (Saha et al. 2006; Yang et al. 2008; Gao et al. 2011; Drbohlav and Krishnamurthy 2010). However, some key features are missing in the hindcasts such as the shifts of the maximum precipitation from the equator to around $15^{\circ} \mathrm{N}$ (Jiang et al. 2012).

Understanding the ISO-Onset-TC connection as we have discussed in this paper could act as a good predictive tool for both monsoon and TC variability. Looking forward, the results of this study could provide further information to augment current predictions techniques of the monsoon during the spring and early summer season, especially for the monsoon onset over Myanmar. 


\section{REFERENCES}

Adames AF (2013) The global scale structure of the MJO. Dissertation, university of Washington

Alexander GR, Keshavamurty UD, Chellapa R, Das S, Pillai P (1978) Fluctuations of monsoon activity. J Meteor Hydrol Geophys 29:76-87

Ashfaq MY, Shi Y, Tung W, Trap R, Gao X, Pal JS, Diffenbaugh NS (2009) Suppression of South Asian summer monsoon precipitation in the 21st century. Geophys Res Lett 36: L01704. doi:10.1029/2008GL036500

Bergeron T (1954) The problem of tropical hurricanes. Q J R Meteorol Soc 80:131-64

Bessafi M, Wheeler MC (2006) Modulation of South Indian Ocean tropical cyclones by the Madden-Julian oscillation and convectively coupled equatorial waves. Mon Wea Rev 134:638-656

Chen Y, Del Genio AD (2008) Evaluation of tropical cloud regimes in observations and a general circulation model. Clim Dyn. doi:10.1007/s00382-008-0386-6

Dakshinamurthy J, Keshavamurthy RN (1976) On oscillations of period around one month in the Indian summer monsoon. Ind J Meteor Geophys 27:201-203

Dee DP, Uppalaa SM, Simmonsa AJ, Berrisforda P, Polia P, Kobayashib S, Andraec U, Balmasedaa MA, Balsamoa G, Bauera P, Bechtolda P, Beljaarsa ACM, Bergd L, Bidlota J, Bormanna N, Delsola C, Dragania R, Fuentesa M, Geera AJ, Haimbergere L, Healya $\mathrm{SB}$, Hersbacha $\mathrm{H}, \mathrm{H}^{\prime}$ olma EV, Isaksena $\mathrm{L}, \mathrm{K}^{\circ}$ allbergc $\mathrm{P}, \mathrm{K}^{*}$ ohlera $\mathrm{M}$, Matricardia $\mathrm{M}$, McNallya AP, Monge-Sanzf BM, Morcrettea J-J, Parkg BK, Peubeya C, de Rosnaya P, Tavolatoe C, Th'epauta J-N and Vitarta F (2011) The ERA-Interim reanalysis: configuration and performance of the data assimilation system. Q J R Meteorol Soc 137:553-597. doi:10.1002/qj.828

DeMaria M, Kaplan J (1999) An updated statistical hurricane intensity prediction scheme (SHIPS) for the Atlantic and eastern North Pacific basins. Weather Forecast 14:326-37

Dhar ON, Nandargi S (2003) Hydrometeorological aspects of floods in India. Nat Hazards 28:1- 33

Drbohlav HK, Krishnamurthy V (2010) Spatial structure, forecast errors, and predictability of the South Asian monsoon in CFS monthly retrospective forecasts. J Clim 23:4750-4769

Emanuel KA (2003) Tropical cyclones. Annu Rev Earth Planet Sci 31: 75-104 
Gao H, Yang S, Kumar A, Hu Z-Z, Huang B, Li Y, Jha B (2011) Variations of the East Asian mei-yu and simulation and prediction by the NCEP Climate Forecast System. J Clim 24:94-108

Geisler JE, Pitcher EJ (1988) On the representation of the 40-50 day oscillation in terms of velocity potential and streamfunction. J Atmos Sci 45(12):1850-1854

Gray WM (1968) Global view of the origin of tropical disturbances and storms. Mon Weather Rev 96:669-700

Gray WM (1979) Hurricanes: their formation, structure and likely role in the general circulation. In: Shaw DB (ed) Meteorology over the Tropical Oceans. Royal Meteorological Society, J Glaisher House, Grenville Place, Bracknell, Berks, pp 155-218

Hendon HH (1986) Streamfunction and velocity potential representation of equatorially trapped waves. J Atmos Sci 43:3038-3042. doi: http://dx.doi.org/10.1175/15200469(1986)043<3038:SAVPRO >2.0.CO;2

Hendon HH, Liebmann B, Glick JD (1998) Oceanic kelvin waves and the madden-julian oscillation. J Atmos Sci 55(1):88-101

Hendon HH, Zhang C, Glick JD (1999) Interannual variation of the Madden-Julian Oscillation during Austral summer. J Clim 12:2538-2550

Higgins RW, Shi W (2001) Intercomparison of the principal modes of interannual and intraseasonal variability of the North American monsoon system. J Clim 14(3):403-417

Ho CH, Kim JH, Jeong JH, Kim HS, Chen D (2006) Variation of tropical cyclone activity in the south Indian Ocean: El Niño-Southern Oscillation and Madden-Julian oscillation effects. J Geophys Res 111:D22101. doi:10.1029/2006JD007289

Htway O, Matsumoto J (2011) Climatological onset dates of summer monsoon over Myanmar. Int J Climatol 31:382-393. doi: 10.1002/joc.2076

Jiang X, Yang S, Li Y, Kumar A, Liu X, Zuo Z, Jha B (2012) Seasonal-to-interannual prediction of the Asian summer monsoon in the NCEP Climate Forecast System Version 2. J Clim. doi:10.1175/JCLI-D-12-00437.1

Kessler WS (2001) EOF representations of the Madden-Julian oscillation and its connection with ENSO. J Clim 14(13):3055-3061

Kikuchi K, Wang B (2010) Formation of tropical cyclones in the northern Indian Ocean associated with two types of tropical intraseasonal oscillation modes. J Meteorol Soc Jpn 88:475-496 
Kistler R, Kalnay E, Collins W, Saha S, White G, Woollen J, Chelliah M, Ebisuzaki W, Kanamitsu M, Kousky V, van den Dool H, Jenne R, Fiorino M (2001) The NCEP-NCAR 50-year reanalysis: monthly means CD-ROM and documentation. Bull Amer Meteor Soc 82:247-267

Krishnamohan KS, Mohankumar K, Joseph PV (2012) The influence of Madden-Julian oscillation in the genesis of North Indian Ocean cyclones. Theor Appl Climatol 109:271282. doi:10.1007/s00704-011-0582-x

Lau WKM, Waliser DE (2005) Intraseasonal Variability of the Atmosphere-Ocean Climate System. Springer, Heidelberg, Germany

Li Z, Yi C, McWilliams JC (2006) Computation of the streamfunction and velocity potential for limited and irregular domains. Mon Wea Rev 134:3384-3394

Lo F, Hendon HH (2000) Empirical extended-range prediction of the Madden-Julian oscillation. Monthly Weather Review 128(7):2528-2543

Lorenz EN (1956) Empirical orthogonal functions and statistical weather prediction. Technical report, Statistical Forecast Project Report 1, Dept. of Meteor, MIT

Madden RA, Julian PR (1971) Detection of a 40-50 day oscillation in the zonal wind in the tropical Pacific. J Atmos Sci 28:702-708

Maloney ED, Hartmann DL (2000) Modulation of eastern North Pacific hurricane by the Madden-Julian oscillation. J Clim 13:1451-1460

Mantua NJ, Hare SR, Zhang Y, Wallace JM, and Francis RC (1997) A pacific interdecadal climate oscillation with impacts on salmon production. BAMS 78(6):10691079. doi:10.1175/1520-0477(1997)

Mao JY, Wu GX (2007) Interannual variability in the onset of the summer monsoon over eastern Bay of Bengal. Theor Appl Climatol 89:155-170

Matsumoto J (1992) The seasonal changes in Asian and Australian monsoon regions. J Meteorol Soc Jpn 70:257-273

Matsumoto J (1997) Seasonal transition of summer rainy season over Indochina and adjacent monsoon region. Adv Atmos Sci 14(2):231-245

Matthews AJ (2000) Propagation mechanisms for the madden-julian oscillation. RMets 126(569):2637-2651

McPhaden MJ, Foltz GR, Lee T, Murty VSN, Ravichandran M, Vecchi GA, Vialard J, Wiggert JD, Yu LC (2009) Ocean-atmosphere interactions during cyclone Nargis. AGU 90:53-60 
Murakami T, Matsumoto J (1994) Summer monsoon over the Asian continent and Western North Pacific. J Meteorol Soc of Jpn 72(5):719-745

Obukhov AM (1960) The statistically orthogonal expansion of empirical functions. Bull. Acad. Sci. USSR Geophys. Ser. (English Transl.) 288-291

Obukhov AM (1947) Statistically homogeneous fields on a sphere. Usp Mat Navk 2: 196-198

Palmer CE (1952) Tropical meteorology. Quart J Roy Meteorol Soc 78:126-164

Raghavan K (1973) Break-monsoon over India. Mon Wea Rev 101(1):33-43

Ramamurthy K (1969) Monsoon of India: Some aspects of "break" in the Indian southwest monsoon during July and August. Forecasting manual part IV: 18.3

Rasmusson EM, Carpenter TH (1983) The relationship between eastern equatorial Pacific sea surface temperature and rainfall over India and Sri Lanka. Mon Wea Rev 111:517528

Riehl H (1950) A model for hurricane formation. J Appl Phys 21:917-25

Saha S, Nadiga S, Thiaw C, Wang J, Wang W, Zhang Q, Van den Dool HM, Pan H-L, Moorthi S, Behringer D, Stokes D, Peña M, Lord S, White G, Ebisuzaki W, Peng P, Xie P (2006) The NCEP climate forecast system. J Clim 19:3483-3517

Shukla J, Paolina DA (1983) The southern oscillation and long range forecasting of summer monsoon over India. Mon Wea Rev 111:1830-1837

Slingo JM, Rowell DP, Sperber KR, Nortley F (1999) On the predictability of the interannual behaviour of the madden-julian oscillation and its relationship with El Nino. Quart J Roy Met Soc 125(554):583-609

Tanaka M (1992) Intraseasonal oscillation and the onset and retreat dates of the summer monsoon over East, Southeast Asia and the Western Pacific region using GMS high cloud amount data. J Meteorol Soc of Jpn 70(1):613-629

Thompson DJW, Wallace JM (2000) Annular modes in the extratropical circulation part I: Month-to-month variability. J Clim 13:1000-1016

Torrence C, Webster P (1999) Interdecadal changes in the ENSO-monsoon system. J Clim 12:2679-2690

Ventrice MJ, Wheeler MC, Hendon HH, Schreck CJ, Thorncroft CD, Kiladis GN (2013) A modified multivariate Madden-Julian oscillation index using velocity potential. Mon Wea Rev 141:12:4197-4210 
Waliser DE (2005) Predictability and forecasting. In: Lau WKM, Waliser DE (eds) Intraseasonal variability of the atmosphere-ocean climate system. Springer, Heidelberg, Germany, pp 389-423

Waliser DE, Lau KM, Kim J-H (1999) The influence of coupled sea surface temperatures on the Madden-Julian Oscillation: A model perturbation experiment. J Atmos Sci 56: $333-358$

Wang B (ed) 2006: The Asian Monsoon. Springer-Praxis

Wang B, Lin H (2002) Season of the Asian-Pacific summer monsoon. J Clim 15:386-398

Wang B, Xie X (1998) Coupled modes of the warm pool climate system. part I: The role of air-sea interaction in maintaining Madden-Julian oscillation. J Clim 11:2116-2135

Wang S-Y, B. Buckley BM, Yoon JH, Fosu BO (2013) Intensification of premonsoon tropical cyclones in the Bay of Bengal and its impacts on Myanmar. J Geophys Res Atmos 118:4373-4384. doi:10.1002/jgrd.50396

Webster PJ (2008) Myanmar's deadly daffodil. Nature Geoscience 488-490

Wheeler MC, Hendon HH (2004) An all-season real-time multivariate MJO index: Development of an index for monitoring and prediction. Mon Weather Rev 132:19171932

Wu GX, Zhang YS (1998) Tibetan Plateau forcing and the timing of the monsoon onset over South Asia and the South China Sea. Mon Wea Rev 126:913-927

Yang S, Zhang Z, Kousky VE, Higgins RW, Yoo S-H, Liang J, Fan Y (2008) Simulations and seasonal prediction of the Asian summer monsoon in the NCEP Climate Forecast System. J Clim 21:3755-3775

Yatagai A, Kamiguchi K, Arakawa O, Hamada A, Yasutomi N, Kitoh A (2012) APHRODITE: Constructing a long-term daily gridded precipitation dataset for asia based on a dense network of rain gauges. Bull Amer Meteor Soc 93:1401-1415. doi: http://dx.doi.org/10.1175/BAMS-D-11-00122.1

Yoon JH, Huang WRJ (2012) Indian monsoon depression. In: Wang S-Y, Gillies RR (eds) Modern Climatology, InTech, Rijeka, Croatia, pp 45-71

Zehr RM (1992) Tropical cyclogenesis in the western North Pacific. In NOAA Tech. Rep. NESDIS 61

Zhang C (2005) Madden-Julian oscillation. Rev Geophys. doi:10.1029/2004RG000158 
Zhang Y, Wallace JM, Battisti DS (1997) ENSO-like interdecadal variability: 1900-93. J Clim 10:1004-1020 